\title{
Variation among Phytophthora cinnamomi isolates from oak forest soils in the eastern United States
}

Jordan E. Eggers

West Virginia University

Follow this and additional works at: https://researchrepository.wvu.edu/etd

\section{Recommended Citation}

Eggers, Jordan E., "Variation among Phytophthora cinnamomi isolates from oak forest soils in the eastern United States" (2009). Graduate Theses, Dissertations, and Problem Reports. 2815.

https://researchrepository.wvu.edu/etd/2815

This Thesis is protected by copyright and/or related rights. It has been brought to you by the The Research Repository @ WVU with permission from the rights-holder(s). You are free to use this Thesis in any way that is permitted by the copyright and related rights legislation that applies to your use. For other uses you must obtain permission from the rights-holder(s) directly, unless additional rights are indicated by a Creative Commons license in the record and/ or on the work itself. This Thesis has been accepted for inclusion in WVU Graduate Theses, Dissertations, and Problem Reports collection by an authorized administrator of The Research Repository @ WVU. For more information, please contact researchrepository@mail.wvu.edu. 


\title{
Variation Among Phytophthora cinnamomi Isolates from Oak Forest Soils in the Eastern United States
}

\author{
by \\ Jordan E. Eggers \\ Thesis submitted to the \\ Davis College of Agriculture, Natural Resources and Design \\ at West Virginia University \\ in partial fulfillment of the requirements \\ for the degree of \\ Master of Science \\ in \\ Plant and Soil Science \\ with an emphasis in Plant Pathology \\ William L. MacDonald, Ph.D., Chair \\ Yilmaz Balci, Ph.D. \\ Daniel G. Panaccione, Ph.D. \\ Joseph B. Morton, Ph.D. \\ Mannon E. Gallegly, Ph.D \\ Division of Plant and Soil Sciences \\ Morgantown, West Virginia \\ 2009
}

Keywords: Phytophthora cinnamomi, intra-species variation, microsatellites

Copyright 2009 Jordan E. Eggers 


\author{
Abstract \\ Variation Among Phytophthora cinnamomi Isolates from Oak Forest Soils \\ in the Eastern United States \\ Jordan E. Eggers
}

Phytophthora cinnamomi isolates, collected from eastern US forest soils, were studied to determine the extent of phenotypic, genotypic, and pathogenic variation present. Four microsatellite loci were targeted for genetic analysis. Phenotypic characteristics measured were sporangia length, width, and length:width ratio; chlamydospore, oogonia, and oospore diameter; antheridia width, colony morphology on PDA; and colony growth rate on clarified V8 agar at $20^{\circ} \mathrm{C}, 24^{\circ} \mathrm{C}, 28^{\circ} \mathrm{C}$, and $32^{\circ} \mathrm{C}$. Red oak logs were inoculated with select isolates to determine relative pathogenicity. Microsatellite analysis showed that the genetic variability of the eastern US oak forest $P$. cinnamomi isolates was low. Isolates were grouped into two microsatellite fingerprint groups (MFG). Isolates in microsatellite group one (MFG1) were characterized by DNA fragment lengths of 120 and $122 \mathrm{bp}$ at locus d39, 169 and $170 \mathrm{bp}$ at locus e16, and 254 and $255 \mathrm{bp}$ at locus g13. Microsatellite Fingerprint Group 2 (MFG2) isolates were characterized by marker sizes of 122 and 124 bp at locus d39, 161 and $163 \mathrm{bp}$ at locus e16, and 247 and $248 \mathrm{bp}$ at locus g13. Similar microsatellite profiles have been found in P. cinnamomi isolate populations from Australia and other regions of the world. The low level of genetic viability and microsatellite marker similarities to $P$. cinnamomi isolates from other continents supports the theory that $P$. cinnamomi is not indigenous to the U.S. and may provide clues as to the origin of US P. cinnamomi. Asexual and sexual spore dimension varied greatly within the populations, but were similar to previous descriptions. Differences in phenotypic characteristics among isolates were most pronounced when data were grouped by MFG, the most significant being colony morphology and growth rate. Isolates expressed either rosaceous or stellate colony morphology. There was some correlation between colony morphology and MFG, but colony morphology alone could not be relied upon to predict the genotype of an isolate. Differences in growth rates of microsatellite fingerprint groups were observed with MFG1 being less tolerant of increased incubation temperatures. No variation in pathogenicity on red oak logs was observed. 


\section{Dedication}

I dedicate this work to my wonderful mother and father, my sisters, my grandparents and my extended family. I thank them for their support and encouragement. 
Acknowledgments

I would like to express my gratitude to Mannon Gallegly for not only sharing his laboratory space with me, but also for sharing his vast knowledge of Phytophthora. Thank you Dan Panaccione and Christine Coyle for the use of your laboratory space, equipment, and your help with molecular techniques. To Deborah Grove and everyone at the Pennsylvania State University Nucleic Acid Facility, thank you for your molecular analysis expertise. Thank you to Soegchan Kang and Michele Mansfield, Pennsylvania State University, for your input and assistance with genetic analysis, and special thank you to Michele for her hospitality during my visits to State College, PA. A big thanks goes out to fellow graduate student, Joseph White, for his assistance with Adobe Photoshop, without which I would still be measuring cankers. Finally, and mostly, I would like to thank William MacDonald and Yilmaz Balci for their guidance, support, and friendship. 
Table of Contents

\section{$\underline{\text { Page }}$}

$\begin{array}{ll}\text { Abstract } & \text { ii }\end{array}$

$\begin{array}{ll}\text { Dedication } & \text { iii }\end{array}$

Acknowledgments $\quad$ iv

Table of Contents $\quad$ v

List of Tables $\quad$ vii

List of Figures

1. Introduction 1

2. Literature Review 2

2.1. Phytophthora cinnamomi 2

2.2. Phenotypic and Genotypic Variation 5

2.3. Variation in Pathogenicity 7

2.4. Variation in other Phytophthora species $\quad 8$

3. Objectives 9

4. Materials and Methods 10

$\begin{array}{lr}\text { 4.1. Isolates } & 10\end{array}$

4.2. Genetic Analysis 12

4.2.1. DNA Extraction 12

$\begin{array}{ll}\text { 4.2.2. Microsatellite PCR } & 13\end{array}$

4.3. Morphological Analysis $\quad 15$

$\begin{array}{ll}\text { 4.3.1. Sporangia } & 15\end{array}$

$\begin{array}{ll}\text { 4.3.2. Chlamydospores } & 16\end{array}$ 
4.3.3. Sexual Reproductive Structures 16

4.3.4. Growth Rate \& Colony Morphology 17

$\begin{array}{lr}\text { 4.4. Pathogenicity } & 18\end{array}$

4.5. Statistical Analysis 19

$\begin{array}{ll}\text { 5. Results } & 22\end{array}$

5.1. Microsatellite Fingerprints 22

5.2. Characteristics of Colony Morphology, Asexual and Sexual Spore Structures

5.3. Colony Growth Rate 32

5.4. Cluster Analysis of Phenotypic Characteristics 34

5.5. Relationship among groups defined by Microsatellite Fingerprint Patterns, Colony Morphology Geographic Origin, and Host 37

5.6. Pathogenic Variation 39

$\begin{array}{ll}\text { 6. Discussion } & 42\end{array}$

6.1. Genetic Variation 42

6.2. Phenotypic Variation 46

6.3. Relationship of Phenotype, Microsatellite Fingerprint, Host and 47 Geographic Origin

6.4. Pathogenic Variation 49

7. Literature Cited 52 
List of Tables

Table 1. Primer sequences 5' to 3' and florescent labels of each primer set.

Table 2. DNA fragment lengths in nucleotides of each microsatellite locus for all isolates.

Table 3. Mean spore measurements, colony morphologies, mean diameter growth rates, isolate geographic origin and host oak type of Phytophthora cinnamomi isolates.

Table 4. Means and standard deviations of morphological characteristics of isolates grouped by microsatellite fingerprint pattern, geographic origin, host, and colony morphology.

Table 5. Mean colony diameter growth rates of isolates grouped by microsatellite fingerprint, isolate geographic origin, host, and colony morphology.

Table 6. Ranked lesion area resulting from inoculations of Phytophthora cinnamomi isolates on to red oak (Quercus rubra) logs.

Table 7. Most commonly observed allele sizes at microsatellite loci d39, e16 and g10 of P. cinnamomi isolates from Australia, Papua New Guinea, and the eastern United States. 
List of Figures

Figure 1. Phytophthora cinnamomi isolate exhibiting the rosaceous colony morphology.

$\underline{\text { Page }}$

Figure 2. Phytophthora cinnamomi isolate exhibiting the stellate colony morphology.

Figure 3. Cluster analysis of isolates based on tested phenotypic variables constructed using Ward's Method. Variables include sporangia length, width, and length:width ratio; chlamydospore, oogonia, and oospore diameters; antheridia width; colony morphology on PDA and colony growth rate at $20^{\circ} \mathrm{C}, 24^{\circ} \mathrm{C}, 28^{\circ} \mathrm{C}$, and $32^{\circ} \mathrm{C}$. Cluster 1 is highlighted in red and Cluster 2 is highlighted in green.

Figure 4. Number of isolates from each phenotypic cluster group (Figure 3) when grouped by microsatellite fingerprint, colony morphology, host oak type, and isolate geographic origin.

Figure 5. Number of isolates in microsatellite fingerprint group 1 (MFG1) and microsatellite fingerprint group 2 (MFG2) in each category of colony morphology, host oak type, and isolate geographic origin groups. Some isolates were not included in all of the groups due to missing host and/or origin data.

Figure 6. Number of isolates with rosaceous and stellate colony morphology in each category of microsatellite fingerprint, host oak type, and isolate geographic origin groups. Some isolates were not included in all of the groups due to missing host and/or origin data.

Figure 7. Comparison of mean lesion areas on red oak logs caused by Phytophthora cinnamomi isolates grouped by microsatellite fingerprint group (MFG), isolate geographic origin, host oak type, and colony morphology. Bars with a different pattern within each isolate group category are significantly different (Tukey-Kramer HSD). 


\section{Introduction}

There has been increasing concern about the role species of Phytophthora play in forest health. Decline of oak and chestnut forests has been a recurring problem in Europe; Phytophthoras are thought to be an important component in the decline complex of both species. As a result numerous studies have been undertaken in Europe to investigate this issue. They have included surveys of soil and trees in oak and chestnut forests in France, England, Scotland, Sweden, Germany, Spain, Italy, Turkey, and Austria (Jung and Blaschke 2000, Balci and Hamschlager 2003a, Balci and Hamschlager 2003b, Vettraino et al. 2005, Jönsson et al. 2005, Chavarriaga 2007). In these studies, a diverse population of Phytophthora species including P. cinnamomi Rands, P. citricola Sawada, P. cactorum (Leb. \& Cohn) Schroet, P. gonapodyides (Peterson) Buisman, P. cambivora (Petri) Buis, P. megasperma (Drechsler), P. quercina Jung, $P$. syringae (Klebahn) Klebahn, P. europaea Hansen \& Jung, P. cryptogea Pethib \& Laff, and previously unclassified species were found associated with soil and diseased plant tissues. Studies by Balci and Halmschlager (2003a and 2003b) and Jung et al. (2000) showed a possible correlation between the presence of Phytophthora species and the occurrence of oak decline in some oak forests.

In the US, Phytophthora ramorum Werres, a newly described species, has been recognized since the 1990's as the cause of mortality of tanoak (Lithocarpus densiflorus (Hook. \& Arn.) Rehd.), coast live oak (Quercus agrifolia Née), California black oak (Q. kelloggii Newb.), and Shreve's oak (Q. parvula Greene var. shrevei (C.H. Mull.) Nixon) in California (Rizzo et al. 2002). The impact of $P$. ramorum on oak ecosystems in California has been the driving force behind many 
of the recent investigations addressing the relationship between Phytophthora species and forest ecosystems in the eastern US.

Until recently, the occurrence of Phytophthora populations in northcentral and northeastern US predominantly oak forest ecosystems was unknown. Beginning in 2004, a survey of oak forest soils in Maryland, Pennsylvania, West Virginia, Ohio, Indiana, Illinois, Michigan, Wisconsin, and Minnesota was conducted by researchers at West Virginia University and the USDA Forest Service to investigate whether Phytophthora species are present in these areas and their role in the health of the hardwood forest if present. This effort resulted in the isolation of seven Phytophthora species, two of which were previously unknown. Among the species found, Phytophthora cinnamomi was most frequently isolated, recovered from $69 \%$ of 171 sites where of Phytophthora species were present (Balci et al. 2007). The common presence of $P$. cinnamomi and its known ability to cause disease warranted further investigation into its role in eastern oak forests. The focus of this study is to evaluate basic biological characteristics of $P$. cinnamomi isolates recovered by Balci et al. (2007).

\section{Literature Review}

\subsection{Phytophthora cinnamomi}

Phytophthora cinnamomi is a cosmopolitan plant pathogen associated with root diseases of numerous woody plants. Since its description as a new species by R.D. Rands in 1922, the list of plants susceptible to $P$. cinnamomi infection has grown to include over 1000 different species, the majority of which are native to Australia (Zentmyer 1980). More plant species likely will be 
added in the future (Hardham 2005). Because of $P$. cinnamomi's broad host range, in favorable conditions the pathogen can rapidly spread and infect many plant species. For this reason, the diseases caused by $P$. cinnamomi are important concerns in agricultural and forest settings as well as in the ornamental trade. A dramatic example of $P$. cinnamomi as a forest pathogen is in Australia, where Eucalyptus and many native plant species are being infected and killed, with losses of large stretches of Eucalyptus forest (Zentmyer 1980). Phytophthora cinnamomi is involved in the decline of Quercus suber L. and Q. ilex L. in the Mediterranean regions of Portugal, Spain and France, and has been observed causing stem cankers on Q. rubra L. in southwest France (Braiser 1994, Robin 1998) and it is the cause of oak mortality in Colima, Mexico (Tainter et al. 2000).

Phytophthora cinnamomi was probably introduced into North America in the Gulf coast and southern Atlantic states region from the late 1700's to the early 1800's through importation of exotic plants (Crandall et al. 1945). Inland spread was most likely facilitated by nursery and horticultural plantings. The first isolation of $P$. cinnamomi in the US was made by White (1930) from diseased rhododendron in New Jersey. Impact of $P$. cinnamomi has been greatest in eastern US forests where American chestnut, chinquapin, Ozark chinquapin and shortleaf pine serve as hosts (Crandall et al. 1945). Phytophthora cinnamomi was first isolated from dying chestnut in 1932, but there are accounts of American chestnut (Castanea dentata (Marsh.) Borkh.) mortality in the US as early as 1824 . Disease symptoms of the dying American chestnuts were similar to those of the "ink disease" that was plaguing European chestnut on the Iberian Peninsula around the same time; $P$. cinnamomi was determined to be the cause of the European chestnut mortality (Crandall 1945). Chestnuts and chinquapins in low lying areas of Mississippi, Alabama, 
Georgia, Tennessee, Virginia, Maryland, and North and South Carolina would either wilt and die or suffer branch dieback over several years, culminating in death. This affliction was originally attributed solely to high water tables and heavy soils, but it is now believed that these trees may have succumbed to $P$. cinnamomi infections. The Ozark chinquapin growing at lower elevations in its native range in Arkansas, Missouri, and Oklahoma began dying around the turn of the century of a similar malady, presumably caused by P. cinnamomi (Crandall et al. 1945). Crandall suggested that the native range of American chestnut, chinquapin, and Ozark chinquapin was greatly altered due to the activity of $P$. cinnamomi.

Phytophthora cinnamomi also is associated with diseases of conifers in the US and is a component of the little leaf disease complex that afflicts shortleaf pine growing on poorly drained clay soils in the southern US (Oak and Tainter 1988). During periods of heavy moisture, soils become waterlogged and predispose tree roots to increased $P$. cinnamomi infection. Phytophthora cinnamomi infects and destroys the feeder roots, reducing their capability for nutrient and water uptake. Infected trees gradually decline and die, and are often attacked by insects in the interim (Oak and Tainter 1988, Zentmyer 1980 and Crandall et al. 1945). Phytophthora cinnamomi also has been shown to cause root rot of other conifers such as Fraser fir in Christmas tree plantations and ornamental and nursery plantings of Douglas-fir (Pratt et al. 1976, Benson and Grand 2000, Kenerley et al. 1984, and Kenerley and Bruck 1983). Phytophthora cinnamomi is highly pathogenic on seedlings of Nobel fir, pacific silver fir, shasta red fir, white fir, and western hemlock and moderately pathogenic on Ponderosa and sugar pine seedlings (Hamm and Hanson 1982). 
The association of P. cinnamomi with oak has received less attention in the United States because the frequency and severity of disease caused by P. cinnamomi is lower than that in Europe and Mexico. There are, however, scattered reports of $P$. cinnamomi infections of oak in forest and landscape settings across the country. Phytophthora cinnamomi has been recovered from bark lesions found on declining Quercus agrifolia, and Q. suber in California (Garbelotto and Huberli 2006 and Mircetich et al. 1977). Wood and Tainter (2002) isolated P. cinnamomi in central Florida from the margins of bleeding cankers on Q. laurifolia Michx. with chlorotic leaves, sparse canopies and little new growth. Barnard (2006) recovered P. cinnamomi from basal cankers on Quercus hemisphaerica Bartram ex Willd. in northcentral Florida. Phytophthora cinnamomi commonly is found in soils of the southeast US and pathogenicity studies with isolates from this region has resulted in the successful infection of white oak (Quercus alba L.), southern red oak (Q. falcata Michx.), and scarlet oak (Q. coccinea Muenchh) (Jordan and Tainter 1996). While no natural infections have been observed on these oak species, the ability of $P$. cinnamomi to cause infections and its common occurrence in forest soils has lead some to propose that $P$. cinnamomi may be an important component of the decline syndrome of eastern oak forests (Jordan and Tainter 1996, Balci et al. 2007).

\subsection{Phenotypic and Genotypic Variation}

To better understand the relationship between $P$. cinnamomi and oak forest health, knowledge of existing $P$. cinnamomi populations is necessary. Determining genetic variability is important for understanding the organism's pathogenic potential. Phenotypic characteristics of $P$. cinnamomi differ among isolates in colony growth (Zentmyer et al. 1976, Shepherd and Pratt 1974), colony morphology (Huberli et al. 2001), sexual and asexual spore characteristics (Erwin and Ribeiro 
1996, Huberli et al. 1997), and heat tolerance (Zentmyer et al. 1976). Variations in sensitivity to chemicals used to control P. cinnamomi also have been observed among isolates. Wilkinson et al. (2001) observed three levels of sensitivity to in vitro phosphite treatments among Australian P. cinnamomi isolates and Benson and Grand (2000) found slight variations in sensitivity to metalaxyl.

Genetic analysis of $P$. cinnamomi populations worldwide has shown that the species consists of multiple genotype groups. Isozyme analysis of $P$. cinnamomi isolates from Australia revealed four multilocus genotype groups (Old et al. 1984). Both the A1 and A2 mating types have two of the four genotype groups (Old et al. 1984). Isozyme analysis of $P$. cinnamomi isolates from Papua New Guinea showed even greater intraspecific diversity (Old et al. 1988). Studies in South Africa using isozyme (Linde et al. 1997), RAPD and RFLP (Linde et al. 1999) analysis also showed genetic diversity within $P$. cinnamomi populations. The most recent genetic analysis, using microsatellite markers, showed that Australian P. cinnamomi populations were represented by three genotype groups and as were most $P$. cinnamomi populations from elsewhere (Dobrowolski et al. 2003). Caetano et al. (2007) found that $P$. cinnamomi infecting Mediterranean Quercus spp. in southern Portugal and southwest Spain clustered into two groups based on AFLP fingerprints and that the isolate clusters closely aligned with the geographic origin. They were able to show that growth rate, optimum growth temperature, and hyphal patterns varied among isolates and that these variations were correlated to isolate geographic origin as well. No work to date has evaluated the genetic diversity of $P$. cinnamomi isolates from forest soils in the eastern US. 


\subsection{Pathogenicity}

Pathogenic variation among $P$. cinnamomi isolates has been well documented. Zentmyer and Guillemet (1981) found that an A1 P. cinnamomi isolate recovered from diseased camellia tissue caused a reduction in growth and root health in both camellia and avocado plants when introduced into the soil. Conversely, when an A2 P. cinnamomi isolate recovered from diseased avocado tissue was introduced into soils of avocado and camellia plants, only the avocado showed a reduction in growth and root health. No significant change in the health of the camellia plants was observed. Phytophthora cinnamomi isolates collected from many different tree species in the eastern and southern US states were used by Crandall et al. (1945) to conduct pathogenicity tests on common forest species. Crandall showed that isolates recovered form Juglans nigra and J. regia in Maryland were able to infect potted black walnut seedlings when soil inoculated, but J. nigra was not susceptible to P. cinnamomi isolates recovered from Pinus resinosa in Maryland or Castanea dentata in Georgia. Hoitink and Schmitthenner (1974) found that $P$. cinnamomi isolates from rhododendron and other ericaceous plants were more virulent on the rhododendron hybrid Purple Splendor than P. cinnamomi isolates from nonericaceous plants. These differences may indicate that there are different strains of $P$. cinnamomi in the US (Crandall 1945). Robin et al. (1998) observed significant variation in pathogenicity of $P$. cinnamomi isolates from different hosts and different regions of the world on different tree species, but could not correlate host origin or isolate origin to this variation. Whether differences in pathogenicity can be attributed to genotypic variation, host specificity, or geographic origin of isolates has yet to be investigated for $P$. cinnamomi isolates in the US. 


\subsection{Variation in other Phytophthora Species}

Within species variation is common among species of Phytophthora. Cohen et al. (2003) divided a population of $P$. citrophthora isolates from Corsica into two distinct genetic groups based on RFLP of mtDNA and variability in microsatellite alleles and ITS sequences. European populations of $P$. quercina were divided into two general groups based on AFLP fingerprint patterns (Cooke et. al. 2005). Lamour and Hausbeck (2002) found that P. capsici isolates from Michigan differed in AFLP patterns as well as sensitivity to mefenoxam. Research also has shown that variation within a species - be it phenotypic, genetic, or pathogenic - may be related to host or geographic origin of the isolate. Bhat et al. (2006) reported that $30.8 \%$ of the AFLP variation observed among $P$. cactorum isolates was associated with host origin and $24.5 \%$ was associated with geographical sources. Phytophthora cactorum isolates from strawberry crown rot are pathogenic on multiple hosts whereas $P$. cactorum from other hosts have limited ability to cause crown rot on strawberry (Hantula et al. 1997, Hantula et al. 2000, Eikemo et al. 2004, Huang et al. 2004, Bhat et al. 2006). Intraspecific genetic and phenotypic variation reported in the genus Phytophthora and the correlation of host and geographic origin to these variations also may be exhibited by the US $P$. cinnamomi population studied in this work. 


\section{Objectives}

The goal of this research was to evaluate the variation among a population of $P$. cinnamomi isolates recovered from soils of eastern US forests dominated by oaks by comparing phenotypic and genotypic characteristics.

Specific objectives of this study were to:

1. evaluate intraspecific diversity by comparing phenotypic characteristics among isolates;

2. evaluate genotypic variation of isolates by comparing DNA fingerprints obtained through the amplification of four length-polymorphic microsatellite loci; and

3. compare the relative pathogenicity of selected isolates within this collection. 


\section{4. Materials and Methods}

\subsection{Isolates}

Phytophthora cinnamomi isolates used in this study were collected by Balci et al. (2007) in a survey of rhizosphere soil surrounding oak trees in Maryland, Pennsylvania, West Virginia, Ohio, and Indiana during the fall and spring of 2004. Isolates of Phytophthora were recovered from soil samples by flooding the soil and baiting them with 3-5 day old leaves of Quercus robur. Foliage that became discolored was examined under light microscope (200X) for the presence of typical sporangia of Phytophthora. Positive leaves were rinsed, patted dry with sterile filter paper, cut into $5 \mathrm{~mm}$ pieces, and plated onto a selective media (PARPNH).

PARPNH consists of V8 agar [100 ml V8 vegetable juice (Campbell Soup Company Camden, $\mathrm{NJ}), 3 \mathrm{~g} \mathrm{CaCO}_{3}, 20 \mathrm{~g}$ agar (Now Foods Bloomingdale, IL), $900 \mathrm{~mL}$ distilled water] amended with $10 \mu \mathrm{g} \mathrm{mL}^{-1}$ pimaricin, $200 \mu \mathrm{g} \mathrm{mL}^{-1}$ ampicillin, $10 \mu \mathrm{g} \mathrm{mL} \mathrm{m}^{-1}$ rifampicin, $25 \mu \mathrm{g} \mathrm{mL}^{-1}$ pentachloronitrobenzene (PCNB), $50 \mu \mathrm{g} \mathrm{mL}^{-1}$ nystatin and $50 \mu \mathrm{g} \mathrm{mL} \mathrm{m}^{-1}$ hymexazol (Balci \& Hamschlager 2003). Mycelium characteristic of Phytophthora was then transferred to V8 agar (V8A). Isolates were identified as $P$. cinnamomi by morphological characteristics and DNA sequencing (Balci et. al. 2007). Additional Phytophthora cinnamomi isolates were recovered from Kentucky and Missouri oak forest soils using the same protocol. Study isolates were subcultured on to V8A from stock cultures. Prior to investigation of morphological, molecular, and pathogenic variation, isolates were inoculated onto live plant tissue as a precaution against development of atypical morphology and the loss of pathogenicity, which can occur after long periods of storage in culture (Huberli et al. 2001, Erwin \& Ribeiro 1996). Examples of atypical morphology are slow growth on agar media at optimum temperatures and colonies that do not 
produce aerial hyphae. Microscopic structures, such as sporangia, could be of irregular shape and size for stored isolates. To minimize the risk of these problems, peppers were inoculated with an agar plug from the edge of a P. cinnamomi colony growing on V8A. Peppers were washed with dish soap and water and surface sterilized by spraying them with $70 \%$ ethanol and patted dry with paper towels. A $5 \times 10 \mathrm{~mm}$ rectangle was cut from the pepper approximately 5 $\mathrm{cm}$ from the stem and $5 \mathrm{~cm}$ from the tip of the pepper using a sterilized scalpel. A similar size agar block taken from the margin of a 3-5 day old $P$. cinnamomi colony growing on V8A was placed into the hole cut in the pepper. Inoculated peppers were incubated for 3-4 days in a moist chamber at room temperature until an area of necrotic tissue developed. Ten to fifteen, 3-5 mm pieces of pepper tissue then were cut from margin of the necrotic area with a sterile scalpel, transferred to PARPNH selective medium, and incubated for $2-3$ days at $20^{\circ} \mathrm{C}$ in the dark. Mycelium growing from pepper tissue into the agar was transferred to V8A and incubated at $20^{\circ} \mathrm{C}$ in the dark.

Single zoospore isolates (SZI) were produced for each isolate after they were recovered from the peppers. This was to ensure that each isolate had only one reproducible microsatellite fingerprint. Microsatellite analysis of an isolate composed of more than one genetically distinct individual could possibly result in a composite DNA fingerprint for that isolate. This composite pattern would make analysis of fingerprints difficult. Single-spore isolates have commonly been used to produce genetically homogenous cultures of $P$. cinnamomi in similar studies (Robin and Desprez-Loustau 1998, Dobrowolski 2003). To obtain single zoospore isolates, a zoospore suspension was produced by washing sporangia (produced as described in section 4.3.1 Sporangia) present on mycelia mats three times with sterile distilled water, chilling mycelium 
and sporangia at $16^{\circ} \mathrm{C}$ for 30 minutes, and incubating them in sterile distilled water at $20^{\circ} \mathrm{C}$ under light. Most zoospores are released from the sporangia after 1 hour (Hwang and Ko 1975). Upon release, $0.5 \mathrm{ml}$ of the zoospore suspension was spread on potato dextrose agar (PDA) (Becton, Dickinson and Co.; Sparks, MD) with a sterile glass rod and incubated in the dark at $20^{\circ} \mathrm{C}$. Plates were inspected for germinating zoospores using a compound microscope 4 hrs after plating. Three germinating zoospores of each isolate were transferred to V8A and incubated at $20^{\circ} \mathrm{C}$. One SZI of each isolate was selected for the study. Stock cultures of SZI were maintained on corn meal agar (Becton, Dickinson, and Company Sparks, MD) slants and corn meal agar slants under mineral oil. Cultures being used for the study were transferred bimonthly on V8A.

\subsection{Genetic Analysis}

All isolates used for the study were analyzed for genetic variability by comparing microsatellite DNA fingerprints. Four microsatellite loci were amplified from DNA extracts of isolates by PCR. PCR products were separated by capillary electrophoresis to produce microsatellite fingerprints.

\subsubsection{DNA Extraction}

Mycelium for DNA extraction was produced by placing one small (approximately $1 \mathrm{~mm}^{3}$ ) agar block taken from the margin of a 3-day-old P. cinnamomi SZI colony into a $1.5 \mathrm{ml}$ Eppendorf microcentrifuge tube containing $750 \mu \mathrm{l}$ of potato dextrose broth (Difco Laboratories, Detroit, MI). The tubes were incubated in the dark at $20^{\circ} \mathrm{C}$ for $5-7$ days. The mycelium in the tubes was separated from the remaining media by centrifuging at $14000 \mathrm{rpm}$ for 2 minutes. The residual 
potato dextrose broth was decanted and the mycelial pellets were frozen at $-20^{\circ} \mathrm{C}$, vacuum freeze dried, and stored at $-20^{\circ} \mathrm{C}$ (Linde et al. 1999).

To extract DNA, $500 \mu \mathrm{l}$ of CTAB extraction buffer $(100 \mathrm{mM}$ Tris- $\mathrm{HCl} \mathrm{pH}$ 8.0, $1.4 \mathrm{NaCl}, 20 \mathrm{mM}$ EDTA and 2\% w/v hexadecyltrimethylammonium bromide) was added to the $1.5 \mathrm{ml}$ microcentrifuge tubes containing freeze dried mycelium, incubated at $65^{\circ} \mathrm{C}$, and pulverized periodically with a sterile plastic pestle. Five hundred microliters of chloroform were added to the tube, mixed thoroughly, and centrifuged at $14500 \mathrm{rpm}$ for 5 minutes (Taylor and Powell 1982). A GeneClean Spin Kit (MP Biomedicals, Solon, OH) then was used to purify the DNA from the supernatant following the instructions in the kit. The recovered DNA was stored in sterile distilled water at $-20^{\circ} \mathrm{C}$.

\subsubsection{Microsatellite PCR}

Fingerprints of each $P$. cinnamomi isolate were produced through amplification of four length polymorphic microsatellite loci. Specific primers were used for each of four loci; d39, g16, and g10; each has a different primer pair specific for that locus. In previous analyses locus g13 was

analyzed with two primer pairs, g13f and g13r1 (g13 primer pair) and g13f and g13r4 (g13(4) primer pair), but only the g13(4) primer set was used and was sufficient for this present analysis (Dobrowolski et al. 2002). Primers d39 and g16 amplify (AC) microsatellite motifs while primers g10 and g13 amplify (AG) microsatellite motifs. Fluorescent labels were attached to the 5' end of one of the primers in each primer set so that each locus was represented by a different color dye (Applied Biosystems, Foster City, CA). Primer sequences and label locations are listed in Table 1. 
Table 1. Primer sequences 5' to 3' and fluorescent labels of each primer set.

\begin{tabular}{cll}
\hline Locus & Primer \# & \multicolumn{1}{c}{ Primer Sequences } \\
\hline \multirow{2}{*}{ d39 } & Primer 1 & 6FAM-GAGAGGTCTTCAGCACGAATG \\
& Primer 2 & ACCACTTTGGTTTCTCGCC \\
\hline \multirow{2}{*}{ e16 } & Primer 1 & VIC-AGATCTCGCACCTCCCTAAAG \\
& Primer 2 & AGGCAAGATTTCGTAGAAGGC \\
\hline \multirow{2}{*}{ g10 } & $\begin{array}{l}\text { Primer 1 } \\
\text { PET-GAACTCCAGCTCCTCCTGC } \\
\text { Primer 2 }\end{array}$ & AAGTTCCCATTTCGCAACAC \\
\hline \multirow{2}{*}{ 13r4 } & Primer 1 & NED-ATGAGCTCACACAAGGTCTCG \\
& Primer 2 & CTTAGGCGTCAAAGTGTCAGC \\
\hline
\end{tabular}

Reaction mixtures consisted of $3 \mu \mathrm{l}$ of DNA solution (approximately $20 \mathrm{ng}$ genomic DNA), 0.1 $\mathrm{mM}$ dNTPs, $2 \mathrm{mM} \mathrm{MgCl} 2,0.1 \mu \mathrm{M}$ forward and reverse primers, $0.5 \mathrm{U}$ GoTaq Flexi DNA polymerase (Promega Corporation, Madison, WI), and $1 \mathrm{X}$ reaction buffer in a $10 \mu \mathrm{l}$ volume. PCR reactions were carried out using a PTC-100 thermocycler (MJ Research, Waltham, MA) with a heated lid and a touchdown program of 1 cycle of $96^{\circ} \mathrm{C}$ for 2 minutes, then 1 amplification cycle of $96^{\circ} \mathrm{C}$ for 30 seconds, $66^{\circ} \mathrm{C}$ for 30 seconds, $72^{\circ} \mathrm{C}$ for 30 seconds, followed by 5 cycles similar to the first amplification cycle except that the annealing temperature was lowered $1^{\circ} \mathrm{C}$ every cycle, then 20 cycles of $96^{\circ} \mathrm{C}$ for 30 seconds, $60^{\circ} \mathrm{C}$ for 30 seconds, $72^{\circ} \mathrm{C}$ for 30 seconds, and a final cycle of $72^{\circ} \mathrm{C}$ for 7 minutes (Dobrowolski 2003). Microsatellite products were separated by capillary electrophoresis at the Pennsylvania State University Biotechnology Institute's Nucleic Acid Facility using standard protocols. Electrophoresis results were analyzed using GeneMapper 4.0 (Applied Biosystems, Foster City, CA). Isolates were assigned to DNA fingerprint groups based on length polymorphisms of microsatellite markers (Lasker and Ran 2004). 


\subsection{Morphological Analysis}

Characteristics of asexual (sporangia and chlamydospores) and sexual (oospores, oogonia, and antheridia) reproductive structures, and colony growth patterns and growth rates of each isolate were measured. Variations among isolates in the aforementioned morphological characteristics were evaluated to distinguish phenotypic subpopulations among the studied P. cinnamomi population.

\subsubsection{Sporangia}

Sporangia were produced by subculturing single zoospore isolates on to fresh V8A and incubating them at $20^{\circ} \mathrm{C}$ for 3-4 days in the dark. Ten, $5 \mathrm{~mm}$ agar plugs were taken from the colony margin and placed on a sterile $90 \mathrm{~mm}$ cellophane disc covering $15 \mathrm{ml}$ of V8A and incubated at $20^{\circ} \mathrm{C}$ for $24 \mathrm{hrs}$ or until the colonies grew to form a solid mat of mycelium covering the cellophane. The mycelium-covered cellophane was transferred to a sterile Petri dish containing $15 \mathrm{ml}$ of $5 \%$ clarified V8 broth (50 ml V8 juice, $1 \mathrm{~g} \mathrm{CaCO}_{3}$, centrifuged at $1500 \mathrm{rpm}$ for 5 minutes, $50 \mathrm{ml}$ supernatant brought up to $1 \mathrm{~L}$ by adding distilled water and sterilized). After incubation at $20^{\circ} \mathrm{C}$ for $24 \mathrm{hrs}$, the V8 broth was removed from the dish and the mycelium washed twice with $20 \mathrm{ml}$ of sterile mineral salt solution and incubated in $20 \mathrm{ml}$ of mineral salt solution at $20^{\circ} \mathrm{C}$ in light conditions (Hwang and Ko 1975). The mineral salt solution was composed of calcium nitrate $(0.01 \mathrm{M})$, potassium nitrate $(0.005 \mathrm{M})$, magnesium sulfate $(0.004$ $\mathrm{M})$, distilled water to make one liter, and $1 \mathrm{ml}$ filter sterilized $(0.22 \mu \mathrm{m}$ pore size $)$ chelated iron (13.05 g ethylene-dinitrilotetraacetic acid, 7.5g KOH, $24.9 \mathrm{~g} \mathrm{FeSO}_{4} \bullet 7 \mathrm{H}_{2} \mathrm{O}$, distilled water to 1 L) added after autoclaving (Chen and Zentmyer 1970). A similar protocol was described by Hwang and Ko (1975) who found that abundant sporangia were produced by incubating 
mycelium in mineral salt solution for $9 \mathrm{hrs,} \mathrm{removing} \mathrm{most} \mathrm{of} \mathrm{the} \mathrm{mineral} \mathrm{salt} \mathrm{solution,} \mathrm{and}$ incubating the mycelium for an additional $12 \mathrm{hrs}$ in moist conditions. The length and width $(\mu \mathrm{m})$ of fifty randomly selected sporangia of each isolate were measured at 200X. Sporangia length and width were used to calculate sporangia length width ratio (Huberli et al. 2001).

\subsubsection{Chlamydospores}

Chlamydospores were produce using a protocol similar to that used for sporangia production. Fifteen $5 \mathrm{~mm}$ plugs from a SZI P. cinnamomi culture growing on V8A were transferred to a V8A plate covered with a $90 \mathrm{~mm}$ cellophane disc and incubated for $2-3$ days at $20^{\circ} \mathrm{C}$ in the dark. The mycelium covered cellophane then was transferred to a sterile empty $100 \mathrm{~mm}$ diameter Petri dish. Fifteen milliliters of clarified V8 (CV8) broth were poured over the mycelium and the Petri dish was incubated in the dark for 2 days at $20^{\circ} \mathrm{C}$. The CV8 broth was decanted and the mycelium was rinsed three times with sterile water and incubated in $5 \mathrm{ml}$ of sterile water under lights for 2 days at room temperature (Huberli 1997, Ribeiro 1983, and Hwang and Ko 1975). The diameters of fifty chlamydospores were measured per isolate at 200X.

\subsubsection{Sexual Reproductive Structures}

Phytophthora cinnamomi is heterothallic and requires two different mating types for oospore production (Zentmyer 1980). All of the isolates collected during the 2004 survey were determined to be the A2 mating type (Balci et al. 2007). Therefore, production of oospores from these isolates was accomplished by pairing isolates with a known A1 mating type of $P$. cinnamomi. The isolates were grown on V8A for 5 days at which time a $5 \mathrm{~mm}$ agar plug was taken from the colony margin and place near the margin of a $60 \mathrm{~mm}$ diameter Petri dish 
containing 10\% clarified V8A (100 ml V8 juice, $2 \mathrm{~g} \mathrm{CaCO}_{3}$, centrifuged for 5 minutes at 1500 rpm, $100 \mathrm{ml}$ of supernatant brought up to $1 \mathrm{~L}$ with distilled water and autoclaved after adding 20 grams of agar). An agar plug from the margin of an A1 P. cinnamomi colony growing on V8A was placed directly across the Petri dish from the isolate to be tested. A mark on the underside of the Petri dish was made to designate the test isolate. Pairings were incubated at $20^{\circ} \mathrm{C}$ in the dark for 3 weeks or until sex bodies formed. Agar blocks taken from the area of mycelium closest to the test isolate were scanned for sex bodies at 400X magnification. The diameter of twenty-five oogonia and oospores as well as the width of ten antheridia were measured for each isolate.

\subsubsection{Growth Rate and Colony Morphology}

Colony growth rate was determined by growing each isolate on 5\% clarified V8A (5\% clarified V8 broth with $20 \mathrm{~g}$ per liter agar added before autoclaving) at $20^{\circ} \mathrm{C}, 24^{\circ} \mathrm{C}, 28^{\circ} \mathrm{C}, 32^{\circ} \mathrm{C}, 34^{\circ} \mathrm{C}$, and $37^{\circ} \mathrm{C}$. Five $\mathrm{mm}$ diameter agar plugs taken from the margins of 5-day-old $P$. cinnamomi SZI colonies growing on V8A were transferred to Petri dishes containing $15 \mathrm{ml}$ of $5 \%$ clarified V8A. Three replicates of each isolate were grown at each temperature. Cultures were initially incubated at room temperature for 48 hours and examined for growth. The margin of the colony was traced with a fine tip marker on the bottom of the Petri dish and the diameter of the colony was measured in millimeters on two axes ninety degrees to each other. The plates were returned to the incubator for an additional 48-72 hours. Duration of the second incubation was varied because some isolates grew slower and required more incubation time for measureable growth. All isolates grown at $28^{\circ} \mathrm{C}$ and $32^{\circ} \mathrm{C}$ also received an extended incubation time. The margin of the colony was traced and the diameter measured again using the same two axes. Total diameter 
growth along the two axes was calculated by subtracting the first measured diameter from the second measured diameter for both axes. To calculate diameter growth per day, the total growth for each axis was divided by the number of incubation days between measurements. The colony growth per day of each axis were added together and divided by two to get the mean diameter growth rate for the plate. Growth rate for the three replicates were summed and divided by three to get mean growth rate per day per isolate.

For comparison of colony morphology, SZI were transferred from V8A cultures to $100 \mathrm{~mm}$ Petri dishes containing $15 \mathrm{ml}$ PDA and incubated at $24^{\circ} \mathrm{C}$ for 10 days. Digital pictures were taken of each isolate. The isolate was recorded as having either a rosaceous or stellate colony pattern (Huberli 2001 and Erwin \& Ribeiro 1996).

\subsection{Pathogenicity}

Isolates were selected for pathogenicity testing based on microsatellite fingerprint grouping. The P. cinnamomi isolates from the study area had microsatellite fingerprint patterns, which allowed them to be divided into two groups. Isolates from each microsatellite group were chosen that encompassed distribution across the study area and host type. Twenty-three isolates were used in the pathogenicity study; with twelve from microsatellite fingerprint group one and eleven isolates from group two (Table 2).

Relative pathogenicity of $P$. cinnamomi isolates was determined by inoculation of cut red oak logs using a protocol adapted from Brasier and Kirk (2001) and Hansen et al. (2005). Red oak

logs were cut from live trees on September $25^{\text {th }}, 2007,48$ hours before inoculation. The ends of 
the $\log$ s were sealed with paraffin wax to retain moisture. Logs were approximately 1 meter in length and ranged $9.75-20 \mathrm{~cm}$ in diameter with an overall mean $\log$ diameter of $12.7 \mathrm{~cm}$.

Eleven of the 23 P. cinnamomi isolates tested were selected at random for inoculation into each $\log$. Therefore, each log was inoculated with eleven different $P$. cinnamomi isolates and each of the 23 isolates being tested was inoculated into at least eleven different logs. A flame sterilized cork borer was used to punch $5 \mathrm{~mm}$ holes through the bark to the cambium of each log. Three sets of 4 holes were punched in each log with one set encircling the log at $20 \mathrm{~cm}$, the second at $50 \mathrm{~cm}$ and the third at $80 \mathrm{~cm}$ from one end of the log. Agar plugs $5 \mathrm{~mm}$ in diameter from isolates actively growing on V8A were randomly inserted into eleven of the holes in each log. A $5 \mathrm{~mm}$ uncolonized V8A plug was inserted into the remaining hole in each log to serve as a

control. The bark plugs were replaced and covered with moistened cotton wool. A $5 \mathrm{~cm}^{2}$ piece of aluminum foil was placed over the cotton wool and secured with duct tape. Inoculated logs were incubated at $20^{\circ} \mathrm{C}$ for 4 weeks. After incubation, the outer bark of each log was removed with a wood chisel; the revealed lesions were outlined with a marker and traced onto paper. The tracings were digitally scanned and the area of each lesion was measured using Adobe Photoshop (Adobe Systems Incorporated, San Jose, CA).

\subsection{Statistical Analysis}

Isolate spore characteristics, colony pattern and growth rate data were grouped based on microsatellite fingerprint pattern, host oak type, isolate geographic origin, and colony morphology. 
Isolates were recovered from the rhizosphere soil of five different oak species. In this study the "host" refers to the oak group of the oak tree from around which the soil was taken, and is designated as either red or white. The oak species from which P. cinnamomi was recovered in the white oak group were $Q$. alba (white oak) and $Q$. prinus (chestnut oak) and the oak species in the red oak group were $Q$. rubra (northern red oak), Q. coccinea (scarlet oak) and Q. velutina (black oak).

Isolate geographic origin groups were formed with respect to the north-south distribution of isolates in the study area. According to Balci et al. (2007), the $40^{\text {th }}$ latitude appears to be the northern boundary for $P$. cinnamomi in eastern US oak forests. Therefore, isolate origin group one consisted of isolates recovered from sites south of the northern limit (between the $37^{\text {th }}$ and $39^{\text {th }}$ latitude) and isolate origin group two isolates were from sites near the suspected northern limit $\left(39^{\text {th }}\right.$ latitude and above) of P. cinnamomi.

In each grouping, morphological characteristics such as sporangia length, width, length:width ratio, chlamydospore diameter, oogonia diameter, oospore diameter, and antheridia width were compared. Mean colony growth rate at $20^{\circ} \mathrm{C}, 24^{\circ} \mathrm{C}, 28^{\circ} \mathrm{C}$ and $32^{\circ} \mathrm{C}$ of isolate groups also were compared (Huberli et al. 2001). Growth rates were log transformed to achieve a normal distribution. The mean differences of each isolate group were tested using ANOVA and TukeyKramer HSD comparison.

A hierarchical cluster analysis was performed using Ward's Method with the variables mean sporangia length, width, and length:width ratio; mean chlamydospore diameter; mean oogonium 
and oospore diameter; mean antheridia width; colony morphology; and mean growth rate at $20^{\circ} \mathrm{C}, 24^{\circ} \mathrm{C}, 28^{\circ} \mathrm{C}$, and $32^{\circ} \mathrm{C}$ (Huberli et al. 2001). Isolates in each phenotypic cluster were analyzed with respect to DNA fingerprint pattern, colony morphology, oak type and geographic origin. Fishers Exact Test was used to analyze microsatellite fingerprint, colony morphology, host oak type, and geographic origin characteristics of the isolates in one phenotypic cluster to isolates grouped together in other clusters.

Lesion areas were log transformed to achieve normal distribution and then tested using ANOVA and Tukey-Kramer HSD based on microsatallite fingerprint groups, isolate geographic origin groups and host oak type groups. Fishers Exact Test was used to analyze the interaction of microsatellite fingerprint, colony morphology, host oak type, and isolate geographic origin groups. All statistical analysis was carried out using JMP 5.0 (SAS Institute Inc., Cary, NC). 


\section{Results}

\subsection{Microsatellite Fingerprints}

Analysis of the four microsatellite loci showed that the $61 P$. cinnamomi isolates could be grouped into two microsatellite fingerprint groups (MFG) (Table 2). Isolates from each group were distinguished from one another using three of the four microsatellite loci. Locus g10 was excluded because fragment lengths were too variable, although there was some fragment length specificity for each group. Microsatellite fingerprint group 1 (MFG1) was characterized by marker sizes of 120 and 122 base pairs at locus d39, 169 and 170 base pairs at locus e16, and 254 and 255 base pairs at locus g13 (Table 2). The most common fragment lengths at the g10 locus for MFG1 were 117 and 120 base pairs, followed by 119 and 120 base pairs and lastly 117, 119, and 120 base pairs. Microsatellite fingerprint group 2 (MFG2) was characterized by marker sizes of 122 and 124 base pairs at locus d39, 161 and 163 base pairs at locus e16, and 247 and 248 base pairs at locus g13. Isolates in MFG2 had an even greater amount of fragment length variability at the g10 locus. The most frequently observed fragments were 115 and 117 base pairs in length (Table 2). Not all isolates from each group had the exact same fingerprint at loci $\mathrm{d} 39$, e16, and g13. Some isolates contained extra fragments or fragments with different lengths at one locus, but were similar at the other two loci. Isolates from MFG1 with slightly different fingerprints were IN 5/5 and MOA5j. Isolates in MFG2 with slightly different fingerprints include PA 1/6 and WVE-UF 5/3. 
Table 2. DNA fragment lengths in nucleotides of each microsatellite locus for all isolates.

\begin{tabular}{|c|c|c|c|c|c|}
\hline Isolate & d39 & e16 & g13 & g10 & $\begin{array}{l}\text { Microsatellite } \\
\text { Group }\end{array}$ \\
\hline IN5/5 & $120 / 124 / 126$ & $169 / 171$ & $249 / 254$ & - & 1 \\
\hline KYMCNP3E & $120 / 122$ & $169 / 171$ & $254 / 255$ & $117 / 120$ & 1 \\
\hline KYWC2E & $120 / 122$ & $169 / 171$ & $254 / 255$ & $117 / 120$ & 1 \\
\hline KYWC4W & $120 / 122$ & $169 / 171$ & $254 / 255$ & $117 / 120$ & 1 \\
\hline MD6/3 & $120 / 122$ & $169 / 171$ & $254 / 255$ & $117 / 120$ & 1 \\
\hline MOA5j & $120 / 122$ & $169 / 171 / 173 / 176$ & $254 / 255$ & $117 / 120$ & 1 \\
\hline MOE1k & $120 / 122$ & $169 / 171$ & $254 / 255$ & $117 / 120$ & 1 \\
\hline $\mathrm{OH} 1 / 3$ & $120 / 122$ & $169 / 171$ & $254 / 255$ & $117 / 120$ & 1 \\
\hline $\mathrm{OH} 13 / 1$ & $120 / 122$ & $169 / 171$ & $254 / 255$ & $117 / 120$ & 1 \\
\hline $\mathrm{OH} 2 / 2$ & $120 / 122$ & $169 / 171$ & $254 / 255$ & $117 / 120$ & 1 \\
\hline ST 6-12 & $120 / 122$ & $169 / 171$ & $254 / 255$ & $117 / 119 / 120$ & 1 \\
\hline ST1-1 & $120 / 122$ & $169 / 171$ & $254 / 255$ & $119 / 120$ & 1 \\
\hline ST11-22 & $120 / 122$ & $169 / 171$ & $254 / 255$ & $119 / 120$ & 1 \\
\hline ST11-23 & $120 / 122$ & $169 / 171$ & $254 / 255$ & $119 / 120$ & 1 \\
\hline ST20-40 & $120 / 122$ & $169 / 171$ & $254 / 255$ & $119 / 120$ & 1 \\
\hline ST24-48 & $120 / 122$ & $169 / 171$ & $254 / 255$ & $117 / 120$ & 1 \\
\hline ST30-61 & $120 / 122$ & $169 / 171$ & $254 / 255$ & - & 1 \\
\hline ST39-79 & $120 / 122$ & $169 / 171$ & $254 / 255$ & $117 / 120$ & 1 \\
\hline ST48-86 & $120 / 122$ & $169 / 171$ & $254 / 255$ & $119 / 120$ & 1 \\
\hline ST48-96 & $120 / 122$ & $169 / 171$ & $254 / 255$ & $117 / 120$ & 1 \\
\hline ST50-101 & $120 / 122$ & $169 / 171$ & $254 / 255$ & $117 / 119 / 120$ & 1 \\
\hline ST5-9 & $120 / 122$ & $169 / 171$ & $254 / 255$ & $117 / 120$ & 1 \\
\hline WV1/3 & $120 / 122$ & $169 / 171$ & $254 / 255$ & $117 / 120$ & 1 \\
\hline WV10/3 & $120 / 122$ & $169 / 171$ & $254 / 255$ & $117 / 120$ & 1 \\
\hline WV $2 / 2$ & $120 / 122$ & $169 / 171$ & $254 / 255$ & $117 / 119 / 120$ & 1 \\
\hline WV3/1 & $120 / 122$ & $169 / 171$ & $254 / 255$ & $117 / 120$ & 1 \\
\hline WV4/2 & $120 / 122$ & $169 / 171$ & $254 / 255$ & $117 / 120$ & 1 \\
\hline WV7/8 & $120 / 122$ & $169 / 171$ & $254 / 255$ & $117 / 120$ & 1 \\
\hline WVE-UF13/3 & $120 / 122$ & $169 / 171$ & $254 / 255$ & $117 / 120$ & 1 \\
\hline
\end{tabular}


Table 2 (Cont.)

\begin{tabular}{|c|c|c|c|c|c|}
\hline Isolate & d39 & e16 & g13 & g10 & $\begin{array}{l}\begin{array}{c}\text { Microsatellite } \\
\text { Group }\end{array} \\
\end{array}$ \\
\hline IN $1 / 2$ & $122 / 124$ & $161 / 163$ & $247 / 248$ & $115 / 117$ & 2 \\
\hline IN10/3 & $122 / 124$ & - & $247 / 248$ & $114 / 115 / 116 / 117$ & 2 \\
\hline IN11/1 & $122 / 124$ & $161 / 163$ & $247 / 248$ & $115 / 117$ & 2 \\
\hline IN14/5 & $122 / 124$ & $161 / 163$ & $247 / 248$ & $114 / 115 / 116 / 117$ & 2 \\
\hline IN2/1 & $122 / 124$ & $161 / 163$ & $247 / 248$ & $114 / 115 / 116 / 117$ & 2 \\
\hline IN $2 / 5$ & $122 / 124$ & $161 / 163$ & $247 / 248$ & $115 / 117$ & 2 \\
\hline $\mathrm{IN} 3 / 2$ & $122 / 124$ & $161 / 163$ & $247 / 248$ & $115 / 117$ & 2 \\
\hline IN $4 / 4$ & $122 / 124$ & $161 / 163$ & $247 / 248$ & $115 / 117 / 119$ & 2 \\
\hline IN6/3 & $122 / 124$ & $161 / 163$ & $247 / 248$ & $114 / 115 / 116 / 117$ & 2 \\
\hline MD 15/2 & $122 / 124$ & $161 / 163$ & $247 / 248$ & $115 / 117$ & 2 \\
\hline $\mathrm{MD} 1 / 4$ & $122 / 124$ & $161 / 163$ & $247 / 248$ & $114 / 115 / 116 / 117$ & 2 \\
\hline $\mathrm{MD} 1 / 5$ & $122 / 124$ & $161 / 163$ & $247 / 248$ & $115 / 117$ & 2 \\
\hline MD11/6 & $122 / 124$ & $161 / 163$ & $247 / 248$ & $115 / 117$ & 2 \\
\hline MD2/1 & $122 / 124$ & $161 / 163$ & $247 / 248$ & $114 / 115 / 116 / 117$ & 2 \\
\hline $\mathrm{MD} 3 / 2$ & $122 / 124$ & $161 / 163$ & $247 / 248$ & $114 / 115 / 116 / 117$ & 2 \\
\hline $\mathrm{MD} 4 / 3$ & $122 / 124$ & $161 / 163$ & $247 / 248$ & $115 / 117$ & 2 \\
\hline $\mathrm{MD} 5 / 2$ & $122 / 124$ & $161 / 163$ & $247 / 248$ & $115 / 117$ & 2 \\
\hline MOE2i & $122 / 124$ & $161 / 163$ & $247 / 248$ & $115 / 116 / 117$ & 2 \\
\hline PA1/6 & $122 / 124$ & $161 / 163 / 169 / 172$ & $247 / 248$ & $103 / 115 / 117$ & 2 \\
\hline $\mathrm{PA} 7 / 4$ & $122 / 124$ & $161 / 163$ & $247 / 248$ & $115 / 117$ & 2 \\
\hline WV8/3B & $122 / 124$ & $161 / 163$ & $247 / 248$ & $115 / 117$ & 2 \\
\hline WV9/1 & $122 / 124$ & $161 / 163$ & $247 / 248$ & $115 / 117$ & 2 \\
\hline WVE-SL2/2 & $122 / 124$ & $161 / 163$ & $247 / 248$ & $115 / 117$ & 2 \\
\hline WVE-UF10/1 & $122 / 124$ & $161 / 163$ & $247 / 248$ & $115 / 117$ & 2 \\
\hline WVE-UF2/4 & $122 / 124$ & $161 / 163$ & $247 / 248$ & $114 / 115 / 116 / 117$ & 2 \\
\hline WVE-UF6/3 & $122 / 124$ & $161 / 163$ & $247 / 248$ & $115 / 117$ & 2 \\
\hline WVE-UF7/3 & $122 / 124$ & $161 / 163$ & $247 / 248$ & $115 / 117$ & 2 \\
\hline WV-GR1/4 & $122 / 124$ & $161 / 163$ & $247 / 248$ & $115 / 116 / 117$ & 2 \\
\hline $\mathrm{WV}-\mathrm{SC} 3 / 3$ & $122 / 124$ & $161 / 163$ & $247 / 248$ & $114 / 115 / 116 / 117$ & 2 \\
\hline WVE-UF 5/3 & $122 / 124$ & $169 / 171$ & $247 / 248$ & $115 / 116 / 117$ & 2 \\
\hline WVE-UF15/5 & $122 / 124$ & $161 / 163$ & $247 / 248$ & $115 / 117$ & 2 \\
\hline WVE-UF4/3 & $122 / 124$ & $161 / 163$ & $247 / 248$ & $115 / 116 / 117$ & 2 \\
\hline
\end{tabular}


Only one isolate from Indiana and one isolate from Maryland were in MFG1, with the remainder from these states in MFG2. All Ohio and Kentucky isolates grouped in MFG1 and all Pennsylvania isolates grouped in MFG2. One of two Missouri isolates was in MFG1 while the other was in MFG2. Of nineteen West Virginia isolates, seven were in MFG1 and twelve were in MFG2. All but one of the isolates recovered from soil from the West Virginia University forest (isolate ID's WVE-UF or WV-UF) were in MFG2.

\subsection{Characteristics of Colony Morphology and Asexual and Sexual Spore Structures}

Two colony morphologies were exhibited by the study isolates (Table 3). Among the $61 P$. cinnamomi isolates, 40 formed a rosaceous colony pattern (Figure 1) and the remaining 21 formed a stellate pattern (Figure 2) when grown on PDA.

Variation in sporangia length, width and length:width ratio of was observed. However, little variation existed in diameters of chlamydospores, oogonia, and oospores and antheridia width among the studied $P$. cinnamomi isolates (Table 3).

Sporangia of all MFG1 isolates were significantly greater in length $\left(P<0.001, R^{2}=0.01\right)$ and width $\left(P<0.001, R^{2}=0.23\right)$ than those of MFG2, but the length:width ratios $\left(P<0.001, R^{2}=0.1\right)$ were significantly smaller (Table 4). No significant differences among the diameters of chlamydospores $(P=0.19)$, oogonia $(P=0.82)$, oospores $(P=0.95)$ or the width of antheridia $(P=0.62)$ were found between the isolates in MFG1 and MFG2 (Table 4). 
Table 3. Mean spore measurements, colony morphologies, mean diameter growth rates, isolate geographic origin and host oak type of Phytophthora cinnamomi isolates.

\begin{tabular}{|c|c|c|c|c|c|c|c|c|c|c|c|c|c|c|c|}
\hline \multirow[b]{3}{*}{ Isolate } & \multirow[b]{3}{*}{ State $^{\mathrm{a}}$} & \multicolumn{7}{|c|}{ Spore Measurement Means } & \multirow{2}{*}{\multicolumn{5}{|c|}{$\begin{array}{c}\text { Mean Growth Rate } \\
(\mathrm{mm} / \text { day })\end{array}$}} & \multirow{2}{*}{\multicolumn{2}{|c|}{ Isolate groups }} \\
\hline & & \multicolumn{3}{|c|}{ Sporangia } & \multirow[b]{2}{*}{$\begin{array}{l}\text { Chlamydospore } \\
\text { Diameter }(\mu \mathrm{m})\end{array}$} & \multirow[b]{2}{*}{$\begin{array}{c}\text { Oogonia } \\
\text { Diameter } \\
(\mu \mathrm{m})\end{array}$} & \multirow[b]{2}{*}{$\begin{array}{c}\text { Oospore } \\
\text { Diameter } \\
(\mu \mathrm{m})\end{array}$} & \multirow[b]{2}{*}{$\begin{array}{c}\text { Antheridia } \\
\text { Width } \\
(\mu \mathrm{m})\end{array}$} & & & & & & & \\
\hline & & $\begin{array}{l}\text { Length } \\
(\mu \mathrm{m})\end{array}$ & $\begin{array}{l}\text { Width } \\
(\mu \mathrm{m})\end{array}$ & $\begin{array}{l}\text { Length to } \\
\text { Width } \\
\text { Ratio } \\
\end{array}$ & & & & & $\begin{array}{c}\text { Colony } \\
\text { Morphology } \\
\text { on PDA } \\
\end{array}$ & $20^{\circ} \mathrm{C}$ & $24^{\circ} \mathrm{C}$ & $28^{\circ} \mathrm{C}$ & $32^{\circ} \mathrm{C}$ & $\begin{array}{c}\text { Geographic } \\
\text { Origin }\end{array}$ & $\begin{array}{c}\text { Oak } \\
\text { Type }^{\mathrm{c}} \\
\end{array}$ \\
\hline $\mathrm{IN} 1 / 2 *$ & IN & $65.5 \pm 12$ & $35.9 \pm 3$ & $1.8 \pm 0.3$ & $47.9 \pm 5$ & $42.3 \pm 3$ & $37.9 \pm 3$ & $16.2 \pm 2$ & Rosaceous & 18.8 & 12.9 & 11.8 & 8.6 & 1 & White \\
\hline IN10/3 & IN & $65.1 \pm 10$ & $35.6 \pm 5$ & $1.9 \pm 0.3$ & $42.6 \pm 4$ & $40.9 \pm 4$ & $37.4 \pm 4$ & $17.7 \pm 2$ & Rosaceous & 23.3 & 12.8 & 13.4 & 7.8 & 1 & White \\
\hline $\mathrm{IN} 3 / 2$ & IN & $73.7 \pm 12$ & $39.4 \pm 4$ & $1.9 \pm 0.3$ & $48.3 \pm 6$ & $42.4 \pm 4$ & $38.3 \pm 4$ & $16.4 \pm 1$ & Rosaceous & 12.9 & 12.9 & 11.9 & 8.6 & 1 & White \\
\hline IN4/4 & IN & $59.5 \pm 11$ & $35.5 \pm 4$ & $1.7 \pm 0.2$ & $41.8 \pm 4$ & $40 \pm 4$ & $36.6 \pm 3$ & $17.7 \pm 2$ & Rosaceous & 18.6 & 12.4 & 11.3 & 8 & 2 & White \\
\hline IN5/5* & IN & $62.9 \pm 11$ & $39.2 \pm 5$ & $1.6 \pm 0.2$ & $51.9 \pm 6$ & $39.4 \pm 3$ & $35.6 \pm 3$ & $17.2 \pm 2$ & Rosaceous & 17.3 & 17.9 & 12.7 & 4.4 & 2 & White \\
\hline IN6/3* & IN & $63.5 \pm 10$ & $35 \pm 3$ & $1.8 \pm 0.3$ & $42.4 \pm 4$ & $41.9 \pm 4$ & $37.9 \pm 3$ & $17.6 \pm 2$ & Rosaceous & 17.3 & 13.9 & 12.6 & 8.1 & 1 & White \\
\hline IN11/1 & IN & $61.1 \pm 8$ & $35.2 \pm 3$ & $1.7 \pm 0.2$ & $45.9 \pm 4$ & $42.3 \pm 4$ & $38.7 \pm 3$ & $17.8 \pm 3$ & Stellate & 14.4 & 12.9 & 12.7 & 7.1 & 1 & Red \\
\hline IN14/5 & IN & $62.6 \pm 12$ & $36.1 \pm 5$ & $1.7 \pm 0.3$ & $46.2 \pm 5$ & $39.9 \pm 3$ & $36.5 \pm 3$ & $16.6 \pm 2$ & Stellate & 17.1 & 13.1 & 12.9 & 5.9 & 1 & Red \\
\hline $\mathrm{IN} 2 / 1$ & IN & $79.1 \pm 17$ & $37.3 \pm 7$ & $2.1 \pm 0.4$ & $49.7 \pm 6$ & $41 \pm 5$ & $37.5 \pm 4$ & $18.6 \pm 1$ & Stellate & 12.3 & 14.1 & 14.9 & 8.3 & 1 & Red \\
\hline $\mathrm{IN} 2 / 5^{*}$ & IN & $72.7 \pm 10$ & $39.1 \pm 4$ & $1.9 \pm 0.3$ & $46.2 \pm 6$ & $41.2 \pm 4$ & $37.8 \pm 4$ & $17.1 \pm 2$ & Stellate & 12.8 & 12.3 & 13.7 & 6.7 & 1 & White \\
\hline KYMCNP3E** & KY & $71.3 \pm 9$ & $43.6 \pm 5$ & $1.6 \pm 0.2$ & $44.9 \pm 6$ & $41.8 \pm 6$ & $36.7 \pm 7$ & $17.3 \pm 2$ & Rosaceous & 19.9 & 19.6 & 17.5 & 3.8 & 1 & White \\
\hline KYWC2E* & KY & $67.6 \pm 10$ & $43.4 \pm 5$ & $1.6 \pm 0.1$ & $47.1 \pm 6$ & $41.9 \pm 3$ & $38.1 \pm 3$ & $17.9 \pm 1$ & Rosaceous & 18.3 & 17.8 & 12.5 & 4.1 & 1 & White \\
\hline KYWC4W & KY & $71.3 \pm 13$ & $39.8 \pm 7$ & $1.8 \pm 0.3$ & $46 \pm 7$ & $41.3 \pm 4$ & $37.5 \pm 3$ & $17.2 \pm 1$ & Rosaceous & 16.1 & 11.9 & 17.5 & 4.4 & 1 & White \\
\hline $\mathrm{MD} 2 / 1^{*}$ & MD & $71.4 \pm 7$ & $39 \pm 4$ & $1.8 \pm 0.2$ & $42.1 \pm 4$ & $41.1 \pm 3$ & $37.4 \pm 3$ & $16.9 \pm 2$ & Rosaceous & 13 & 11.4 & 12.2 & 9.2 & 2 & White \\
\hline $\mathrm{MD} 3 / 2$ & MD & $61.9 \pm 10$ & $35.4 \pm 4$ & $1.8 \pm 0.2$ & $44.5 \pm 4$ & $41 \pm 3$ & $37 \pm 3$ & $17.7 \pm 2$ & Rosaceous & 15.5 & 14.9 & 16.6 & 5.6 & 2 & Red \\
\hline MD5/2 & MD & $64.7 \pm 9$ & $34.9 \pm 3$ & $1.9 \pm 0.3$ & $47.4 \pm 7$ & $41.4 \pm 4$ & $37.4 \pm 4$ & $16.3 \pm 1$ & Rosaceous & 13.6 & 10.8 & 12.6 & 7.7 & 2 & White \\
\hline MD6/3* & MD & $59.6 \pm 9$ & $38.9 \pm 5$ & $1.5 \pm 0.2$ & $49.3 \pm 8$ & $41.7 \pm 3$ & $38.1 \pm 3$ & $16.3 \pm 1$ & Rosaceous & 15.8 & 11.8 & 12.8 & 3.5 & 2 & White \\
\hline $\mathrm{MD} 1 / 4$ & MD & $60.2 \pm 8$ & $33.1 \pm 2$ & $1.8 \pm 0.2$ & $49 \pm 5$ & $40.5 \pm 5$ & $36.4 \pm 4$ & $18.7 \pm 3$ & Rosaceous & 22 & 10.8 & 13.4 & 8.1 & 2 & NA \\
\hline $\mathrm{MD} 1 / 5$ & MD & $63.5 \pm 10$ & $37.4 \pm 5$ & $1.7 \pm 0.2$ & $48.3 \pm 7$ & $42.8 \pm 4$ & $38.3 \pm 3$ & $15.7 \pm 1$ & Stellate & 26.7 & 14.2 & 13.5 & 7.8 & 2 & Red \\
\hline MD11/6 & MD & $61.1 \pm 10$ & $35.1 \pm 4$ & $1.7 \pm 0.2$ & $44.6 \pm 5$ & $39.6 \pm 4$ & $36.4 \pm 4$ & $16.6 \pm 2$ & Stellate & 18.7 & 11.9 & 11.8 & 6.8 & 2 & Red \\
\hline MD15/2* & MD & $71.2 \pm 11$ & $35 \pm 3$ & $2 \pm 0.3$ & $43.1 \pm 5$ & $40.9 \pm 5$ & $37.1 \pm 4$ & $17.4 \pm 2$ & Stellate & 14.5 & 11.8 & 12.2 & 6.1 & 2 & NA \\
\hline $\mathrm{MD} 4 / 3$ & MD & $58.6 \pm 8$ & $36.2 \pm 3$ & $1.6 \pm 0.2$ & $47.7 \pm 6$ & $43.3 \pm 4$ & $38 \pm 3$ & $16.7 \pm 1$ & Stellate & 16 & 14.2 & 11.2 & 7.3 & 2 & Red \\
\hline
\end{tabular}


Table 3 (Cont.)

\begin{tabular}{|c|c|c|c|c|c|c|c|c|c|c|c|c|c|c|c|}
\hline \multirow[b]{3}{*}{ Isolate } & \multirow[b]{3}{*}{ State $^{\mathrm{a}}$} & \multicolumn{7}{|c|}{ Spore Measurement Means } & \multirow[b]{3}{*}{ gy } & \multirow{2}{*}{\multicolumn{4}{|c|}{ Mean Growth Rate (mm/day) }} & \multirow{2}{*}{\multicolumn{2}{|c|}{ Isolate groups }} \\
\hline & & \multicolumn{3}{|c|}{ Sporangia } & \multirow[b]{2}{*}{$\begin{array}{l}\text { Chlamydospore } \\
\text { Diameter }(\mu \mathrm{m})\end{array}$} & \multirow[b]{2}{*}{$\begin{array}{c}\text { Oogonia } \\
\text { Diameter } \\
(\mu \mathrm{m})\end{array}$} & \multirow[b]{2}{*}{$\begin{array}{c}\text { Oospore } \\
\text { Diameter } \\
(\mu \mathrm{m})\end{array}$} & \multirow[b]{2}{*}{$\begin{array}{c}\text { Antheridia } \\
\text { Width } \\
(\mu \mathrm{m})\end{array}$} & & & & & & & \\
\hline & & $\begin{array}{l}\text { Length } \\
(\mu \mathrm{m})\end{array}$ & $\begin{array}{l}\text { Width } \\
(\mu \mathrm{m})\end{array}$ & $\begin{array}{c}\text { Length to } \\
\text { Width } \\
\text { Ratio } \\
\end{array}$ & & & & & & $20^{\circ} \mathrm{C}$ & $24^{\circ} \mathrm{C}$ & $28^{\circ} \mathrm{C}$ & $32^{\circ} \mathrm{C}$ & $\begin{array}{c}\text { Geographic } \\
\text { Origin }^{b}\end{array}$ & $\begin{array}{l}\text { Oak } \\
\text { Type }^{c}\end{array}$ \\
\hline MOA5j* & MO & $69.2 \pm 8$ & $42.1 \pm 5$ & $1.7 \pm 0.2$ & $48.3 \pm 5$ & $40.2 \pm 3$ & $36.7 \pm 3$ & $16.4 \pm 1$ & Rosaceous & 17.9 & 17.9 & 10.8 & 3.2 & 1 & NA \\
\hline MOE1k & MO & $82 \pm 9$ & $50.6 \pm 4$ & $1.6 \pm 0.4$ & $43.9 \pm 7$ & $44.2 \pm 3$ & $40.3 \pm 3$ & $17.4 \pm 2$ & Rosaceous & 18 & 17.8 & 11.3 & 4.1 & 1 & NA \\
\hline MOE2i* & MO & $70.3 \pm 16$ & $36.5 \pm 3$ & $1.9 \pm 0.5$ & $44.4 \pm 4$ & $40.2 \pm 4$ & $36.6 \pm 4$ & $15.2 \pm 1$ & Stellate & 16.1 & 15.9 & 13.7 & 8.1 & 1 & NA \\
\hline $\mathrm{OH} 1 / 3$ & $\mathrm{OH}$ & $66.1 \pm 11$ & $39.9 \pm 6$ & $1.7 \pm 0.2$ & $48.8 \pm 6$ & $39.2 \pm 2$ & $35.5 \pm 2$ & $16.5 \pm 1$ & Rosaceous & 17.2 & 13.1 & 9.8 & 5.4 & 2 & White \\
\hline $\mathrm{OH} 2 / 2 *$ & $\mathrm{OH}$ & $71.1 \pm 12$ & $43.6 \pm 6$ & $1.6 \pm 0.2$ & $47.6 \pm 6$ & $40.8 \pm 3$ & $36.8 \pm 3$ & $16.9 \pm 1$ & Rosaceous & 17.3 & 15.9 & 10.9 & 5.1 & 2 & White \\
\hline OH13/1 & $\mathrm{OH}$ & $67.7 \pm 13$ & $40.3 \pm 5$ & $1.7 \pm 0.2$ & $45.7 \pm 7$ & $40.8 \pm 3$ & $36.8 \pm 3$ & $18.4 \pm 2$ & Rosaceous & 17.6 & 14.5 & 16.6 & 5.1 & 2 & Red \\
\hline ST $1-1 *$ & $\mathrm{OH}$ & $68.1 \pm 14$ & $40.3 \pm 5$ & $1.7 \pm 0.2$ & $46.8 \pm 8$ & $39.5 \pm 4$ & $36.1 \pm 3$ & $19.4 \pm 6$ & Rosaceous & 15.8 & 16.2 & 10.3 & 5.3 & 2 & White \\
\hline ST $11-22 *$ & $\mathrm{OH}$ & $72.6 \pm 15$ & $40.9 \pm 4$ & $1.8 \pm 0.3$ & $40.2 \pm 5$ & $41.1 \pm 3$ & $37.4 \pm 2$ & $16.6 \pm 1$ & Rosaceous & 16.8 & 15.7 & 10.4 & 4.2 & 2 & White \\
\hline ST $11-23$ & $\mathrm{OH}$ & $81.1 \pm 21$ & $43.8 \pm 7$ & $1.9 \pm 0.4$ & $39.2 \pm 5$ & $41.5 \pm 4$ & $38 \pm 4$ & $16.7 \pm 3$ & Rosaceous & 15.5 & 14.4 & 11.5 & 4.5 & 2 & White \\
\hline ST $20-40$ & $\mathrm{OH}$ & $66.3 \pm 15$ & $42.1 \pm 6$ & $1.6 \pm 0.3$ & $39.1 \pm 7$ & $40.4 \pm 4$ & $36.4 \pm 4$ & $17.7 \pm 2$ & Rosaceous & 16.8 & 16.9 & 11 & 5.5 & 2 & White \\
\hline ST $24-48$ & $\mathrm{OH}$ & $63.3 \pm 11$ & $41.1 \pm 6$ & $1.6 \pm 0.2$ & $35.4 \pm 6$ & $39.6 \pm 3$ & $35.8 \pm 3$ & $17.1 \pm 2$ & Rosaceous & 15.3 & 14 & 11.6 & 5.5 & 2 & White \\
\hline ST 30-61 & $\mathrm{OH}$ & $58.7 \pm 10$ & $42.1 \pm 5$ & $1.4 \pm 0.1$ & $46.4 \pm 8$ & $34.7 \pm 4$ & $31.4 \pm 4$ & $17.2 \pm 2$ & Rosaceous & 13 & 15.9 & 10.5 & 5.4 & 2 & White \\
\hline ST $39-79$ & $\mathrm{OH}$ & $64.3 \pm 10$ & $40 \pm 5$ & $1.6 \pm 0.2$ & $49.9 \pm 5$ & $41.9 \pm 3$ & $37.2 \pm 6$ & $17 \pm 2$ & Rosaceous & 16.3 & 15.8 & 12.2 & 5.7 & 2 & White \\
\hline ST $43-86^{*}$ & $\mathrm{OH}$ & $64.5 \pm 13$ & $41.3 \pm 5$ & $1.6 \pm 0.2$ & $39.7 \pm 6$ & $42.2 \pm 3$ & $38.8 \pm 3$ & $17.2 \pm 2$ & Rosaceous & 17 & 16.9 & 11.3 & 5 & 2 & White \\
\hline ST 48-96 & $\mathrm{OH}$ & $69.4 \pm 16$ & $41.3 \pm 6$ & $1.7 \pm 0.2$ & $47.6 \pm 7$ & $40.8 \pm 3$ & $36.9 \pm 2$ & $17.7 \pm 2$ & Rosaceous & 16.5 & 17.4 & 11.7 & 8 & 2 & White \\
\hline ST 50-101 & $\mathrm{OH}$ & $65.1 \pm 11$ & $40.4 \pm 5$ & $1.6 \pm 0.2$ & $45.7 \pm 5$ & $39.7 \pm 3$ & $35.6 \pm 4$ & $16.5 \pm 1$ & Rosaceous & 15.9 & 15.3 & 11.1 & 3.5 & 2 & White \\
\hline ST 5-9 & $\mathrm{OH}$ & $53.8 \pm 10$ & $36.7 \pm 5$ & $1.5 \pm 0.2$ & $47.6 \pm 5$ & $39 \pm 3$ & $35.9 \pm 3$ & $17.7 \pm 2$ & Rosaceous & 15.9 & 15.3 & 11.2 & 5.9 & 2 & White \\
\hline ST 6-12 & $\mathrm{OH}$ & $64.7 \pm 13$ & $43.5 \pm 7$ & $1.5 \pm 0.2$ & $49 \pm 7$ & $37.9 \pm 3$ & $34.9 \pm 2$ & $17.2 \pm 2$ & Rosaceous & 15.9 & 16.5 & 10.4 & 4 & 2 & White \\
\hline PA1/6* & PA & $61.9 \pm 8$ & $36.6 \pm 4$ & $1.7 \pm 0.3$ & $51.7 \pm 7$ & $37.3 \pm 4$ & $33.9 \pm 4$ & $18.8 \pm 3$ & Rosaceous & 14.3 & 11.1 & 13.1 & 7.9 & 2 & Red \\
\hline PA7/4* & $\mathrm{PA}$ & $60.7 \pm 9$ & $36.5 \pm 3$ & $1.7 \pm 0.2$ & $44.6 \pm 5$ & $38.6 \pm 4$ & $34.6 \pm 4$ & $16.3 \pm 2$ & Stellate & 14.6 & 11 & 12.4 & 8 & 2 & White \\
\hline
\end{tabular}


Table 3 (Cont.)

\begin{tabular}{|c|c|c|c|c|c|c|c|c|c|c|c|c|c|c|c|}
\hline \multirow[b]{3}{*}{ Isolate } & \multirow[b]{3}{*}{ State $^{\mathrm{a}}$} & \multicolumn{7}{|c|}{ Spore Measurement Means } & \multirow{2}{*}{\multicolumn{5}{|c|}{$\begin{array}{l}\text { Mean Growth Rate } \\
\text { (mm/day) }\end{array}$}} & \multirow{2}{*}{\multicolumn{2}{|c|}{ Isolate groups }} \\
\hline & & \multicolumn{3}{|c|}{ Sporangia } & \multirow[b]{2}{*}{$\begin{array}{l}\text { Chlamydospore } \\
\text { Diameter }(\mu \mathrm{m})\end{array}$} & \multirow{2}{*}{$\begin{array}{c}\text { Oogonia } \\
\text { Diameter } \\
(\mu \mathrm{m}) \\
\end{array}$} & \multirow[b]{2}{*}{$\begin{array}{l}\text { Oospore } \\
\text { Diameter } \\
(\mu \mathrm{m})\end{array}$} & \multirow{2}{*}{$\begin{array}{l}\text { Antheridia } \\
\text { Width } \\
(\mu \mathrm{m})\end{array}$} & & & & & & & \\
\hline & & $\begin{array}{l}\text { Length } \\
(\mu \mathrm{m})\end{array}$ & $\begin{array}{l}\text { Width } \\
(\mu \mathrm{m})\end{array}$ & $\begin{array}{c}\text { Length:Width } \\
\text { Ratio } \\
\end{array}$ & & & & & $\begin{array}{l}\text { Colony } \\
\text { Morphology } \\
\text { on PDA } \\
\end{array}$ & $20^{\circ} \mathrm{C}$ & $24^{\circ} \mathrm{C}$ & $28^{\circ} \mathrm{C}$ & $32^{\circ} \mathrm{C}$ & $\begin{array}{c}\text { Geographic } \\
\text { Origin }\end{array}$ & $\begin{array}{c}\text { Oak } \\
\text { Type }^{\mathrm{c}}\end{array}$ \\
\hline GR $1 / 4$ & WV & $65.5 \pm 8$ & $34.9 \pm 3$ & $1.9 \pm 0.2$ & $41.9 \pm 4$ & $38.3 \pm 5$ & $35.3 \pm 4$ & $17.1 \pm 2$ & Rosaceous & 15.8 & 14.1 & 16.9 & 6.4 & 2 & Red \\
\hline WV10/3* & WV & $71.8 \pm 13$ & $40.6 \pm 6$ & $1.8 \pm 0.3$ & $47.1 \pm 5$ & $41 \pm 3$ & $36.8 \pm 3$ & $17.7 \pm 2$ & Rosaceous & 18.8 & 18 & 11 & 5.5 & 1 & Red \\
\hline $\mathrm{WV} 2 / 2^{*}$ & WV & $71.4 \pm 12$ & $43 \pm 5$ & $1.7 \pm 0.2$ & $45 \pm 6$ & $42.9 \pm 3$ & $37.5 \pm 6$ & $17.4 \pm 1$ & Rosaceous & 27.3 & 17.9 & 13.6 & 6.5 & 1 & White \\
\hline WV3/1 & WV & $69.4 \pm 11$ & $42.4 \pm 4$ & $1.6 \pm 0.2$ & $44.6 \pm 5$ & $41.1 \pm 6$ & $37.2 \pm 6$ & $18.9 \pm 2$ & Rosaceous & 28.3 & 18.5 & 18.5 & 5.8 & 1 & White \\
\hline WV4/2 & WV & $68.9 \pm 13$ & $41.4 \pm 6$ & $1.7 \pm 0.2$ & $49.7 \pm 6$ & $42.8 \pm 3$ & $39 \pm 3$ & $20.8 \pm 6$ & Rosaceous & 29.5 & 20.4 & 12.7 & 6.9 & 1 & Red \\
\hline WV7/8 & WV & $68 \pm 13$ & $40.9 \pm 6$ & $1.7 \pm 0.2$ & $46.9 \pm 7$ & $41.2 \pm 3$ & $37.9 \pm 2$ & $17.1 \pm 1$ & Rosaceous & 18.6 & 17.1 & 12.9 & 5.7 & 1 & White \\
\hline WVE-SL2/2 & WV & $65.7 \pm 11$ & $36.8 \pm 4$ & $1.8 \pm 0.3$ & $45.9 \pm 7$ & $39.4 \pm 6$ & $35.2 \pm 5$ & $17.6 \pm 3$ & Rosaceous & 15 & 12.7 & 14.7 & 7 & 1 & Red \\
\hline WVE-UF10/1 & WV & $66.6 \pm 9$ & $36.3 \pm 4$ & $1.9 \pm 0.3$ & $45.3 \pm 7$ & $40.1 \pm 4$ & $35.4 \pm 3$ & $15.8 \pm 2$ & Rosaceous & 15.1 & 12.6 & 14 & 6.4 & 2 & Red \\
\hline WVE-UF13/3* & WV & $67.7 \pm 7$ & $44.5 \pm 5$ & $1.5 \pm 0.2$ & $40.8 \pm 5$ & $39.8 \pm 2$ & $36.4 \pm 2$ & $16.8 \pm 1$ & Rosaceous & 15.7 & 14.5 & 9.6 & 4.1 & 2 & Red \\
\hline WV-UF15/5* & WV & $58.1 \pm 10$ & $34.8 \pm 3$ & $1.7 \pm 0.2$ & $43.7 \pm 5$ & $39 \pm 5$ & $35 \pm 4$ & $17 \pm 2$ & Rosaceous & 14.3 & 15.7 & 15.3 & 4.2 & 2 & Red \\
\hline WV-UF5/3* & WV & $55.9 \pm 9$ & $34.1 \pm 4$ & $1.7 \pm 0.3$ & $35.3 \pm 4$ & $36.6 \pm 4$ & $33.5 \pm 3$ & $16.1 \pm 2$ & Rosaceous & 21.3 & 14 & 11 & 2.6 & 2 & White \\
\hline WV1/3 & WV & $81.4 \pm 11$ & $45.4 \pm 5$ & $1.8 \pm 0.2$ & $49 \pm 5$ & $39.4 \pm 4$ & $34.9 \pm 4$ & $16 \pm 1$ & Stellate & 16 & 16.8 & 9.9 & 3.4 & 1 & White \\
\hline WV8/3B* & WV & $62.3 \pm 13$ & $35.4 \pm 4$ & $1.8 \pm 0.3$ & $47 \pm 6$ & $41.8 \pm 3$ & $38 \pm 3$ & $17.3 \pm 2$ & Stellate & 15 & 13.4 & 11.5 & 6.9 & 1 & Red \\
\hline WV9/1 & WV & $67.7 \pm 10$ & $38.7 \pm 4$ & $1.8 \pm 0.2$ & $44.2 \pm 5$ & $39.3 \pm 6$ & $36 \pm 5$ & $18.5 \pm 2$ & Stellate & 13.9 & 11.4 & 12 & 6.1 & 1 & White \\
\hline WVE-UF2/4 & WV & $65.1 \pm 12$ & $36.3 \pm 4$ & $1.8 \pm 0.3$ & $46.8 \pm 5$ & $39.5 \pm 4$ & $35.4 \pm 4$ & $16.8 \pm 2$ & Stellate & 14.6 & 13 & 13.6 & 5.5 & 2 & Red \\
\hline WVE-UF6/3 & WV & $69.4 \pm 7$ & $37.6 \pm 3$ & $1.9 \pm 0.2$ & $49.7 \pm 5$ & $39 \pm 4$ & $35.1 \pm 4$ & $17.6 \pm 3$ & Stellate & 15.8 & 13.3 & 13.2 & 5.9 & 2 & White \\
\hline WVE-UF7/3 & WV & $68.5 \pm 11$ & $37.2 \pm 4$ & $1.9 \pm 0.3$ & $46.1 \pm 6$ & $42.1 \pm 4$ & $38.4 \pm 4$ & $18.3 \pm 3$ & Stellate & 14.3 & 13.1 & 13.5 & 6.5 & 2 & White \\
\hline WV-SC $3 / 3$ & WV & $60.1 \pm 8$ & $36.3 \pm 4$ & $1.7 \pm 0.1$ & $44.5 \pm 3$ & $39 \pm 3$ & $35.4 \pm 3$ & $19 \pm 8$ & Stellate & 15.3 & 12.4 & 11.8 & 5.9 & 1 & NA \\
\hline WV-UF4/3 & WV & $69.7 \pm 13$ & $36.4 \pm 4$ & $1.9 \pm 0.3$ & $43.4 \pm 5$ & $41.2 \pm 5$ & $37 \pm 5$ & $17.9 \pm 3$ & Stellate & 15.2 & 13.2 & 13.7 & 6 & 2 & White \\
\hline Average & & $66.6 \pm 13$ & $38.9 \pm 6$ & $1.7 \pm 0.3$ & $45.3 \pm 7$ & $40.6 \pm 4$ & $36.8 \pm 4$ & $17.3 \pm 2$ & & 17.0 & 14.5 & 12.7 & 6.0 & & \\
\hline Max & & 137 & 78 & 3.56 & 70 & 52 & 47 & 40 & & 30.5 & 20.5 & 19 & 10.5 & & \\
\hline Min & & 37 & 24 & 0.75 & 22 & 19 & 13 & 12 & & 12 & 9.8 & 9 & 2.4 & & \\
\hline
\end{tabular}

a $\mathrm{IN}=$ Indiana, $\mathrm{KY}=$ Kentucky, $\mathrm{MD}=$ Maryland, $\mathrm{MO}=$ Missouri, $\mathrm{OH}=\mathrm{Ohio}, \mathrm{PA}=$ Pennsylvania, WV=West Virginia.

b $1=$ Isolates collected from sites between the 37 and $39^{\circ}$ latitude, $2=$ Isolates collected from sites north of the $39^{\text {th }}$ latitude.

${ }^{\text {c }}$ White= Isolates collected from the rhizosphere soil of either $Q$. alba (white oak) or $Q$. prinus (chestnut oak), Red=Isolates collected from the rhizosphere soil of either $Q$. rubra (northern red oak), Q. coccinea (scarlet oak) or $Q$. velutina (black oak).

* Isolates used in pathogenicity tests. 


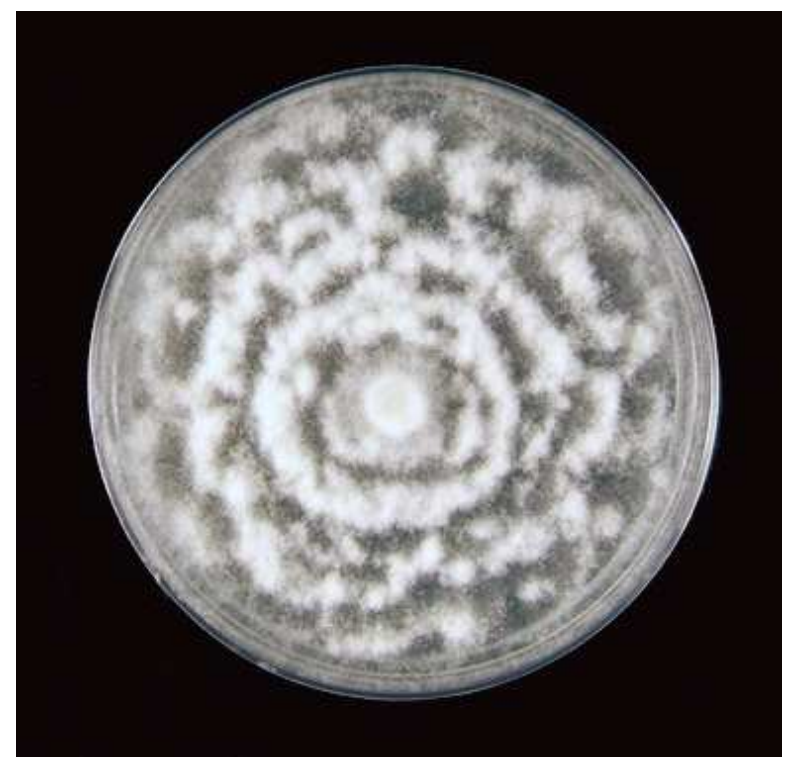

Figure 1. Phytophthora cinnamomi isolate exhibiting the rosaceous colony morphology

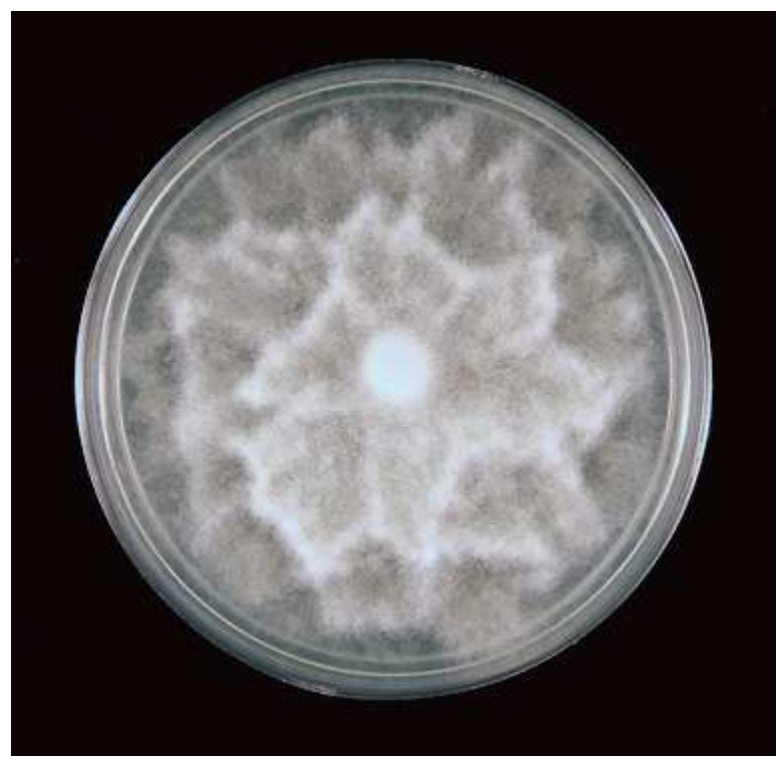

Figure 2. Phytophthora cinnamomi isolate exhibiting the stellate colony morphology 
Isolate means organized by latitude of site origin showed that isolates obtained between the $37^{\text {th }}$ and $39^{\text {th }}$ latitude had significantly greater mean sporangia length $\left(P<0.001, R^{2}=0.03\right)$, width $\left(P<0.001, \mathrm{R}^{2}=0.01\right)$, and length:width ratio $\left(P<0.001, R^{2}=0.01\right)$ as well as chlamydospore $\left(P<0.001, R^{2}=0.007\right)$, oogonia $\left(P<0.001, R^{2}=0.02\right)$ and oospore diameter $\left(P<0.001, R^{2}=0.01\right)$ (Table 4) than isolates from above the $39^{\text {th }}$ latitude. Antheridia width $(P=0.22)$ did not differ between groups (Table 4).

Mean sporangia length $\left(P<0.001, R^{2}=0.01\right)$, width $\left(P<0.001, R^{2}=0.04\right)$, and length:width ratio $\left(P<0.001, R^{2}=0.005\right)$ and chlamydospore diameter $\left(P<0.001, R^{2}=0.008\right)$ differed significantly between isolates recovered from the rhizosphere of red versus white oaks. Sporangia of isolates recovered from white oak rhizosphere soil averaged $2.7 \mathrm{~mm}$ longer and $2.5 \mathrm{~mm}$ wider than isolates from red oak rhizosphere soil. However, the average chlamydospore diameter of isolates from red oak soil was $1.3 \mathrm{~mm}$ greater than chlamydospores of isolates from white oak soils (table 4). Mean oogonium $(P=0.81)$ and oospore $(P=0.91)$ diameter and antheridium width $(P=0.17)$ did not differ significantly (Table 4).

When spore characteristics of isolates based on colony morphology were compared, sporangia of isolates with a rosaceous colony pattern were slightly wider $\left(P<0.001, R^{2}=0.01\right)$. In contrast, sporangium length:width ratio $\left(P<0.001, R^{2}=0.05\right)$ and chlamydospore diameter $(P<0.01$, $R^{2}=0.003$ ) of isolates with a stellate colony appearance were larger (Table 4). Sporangia length ( $P=0.19)$, oogonia diameter $(P=0.28)$, oospore diameter $(\mathrm{P}=0.22)$, and antheridia width $(\mathrm{P}=0.23)$ did not differ significantly. 
Table 4. Means and standard deviations of morphological characteristics of isolates grouped by microsatellite fingerprint pattern, geographic origin, host, and colony morphology. ${ }^{a}$

\begin{tabular}{|c|c|c|c|c|c|c|c|c|}
\hline Group & $\begin{array}{l}\text { Group } \\
\text { Category }\end{array}$ & $\begin{array}{c}\text { Sporangia } \\
\text { Length }(\mu \mathrm{m})\end{array}$ & $\begin{array}{c}\text { Sporangia } \\
\text { Width }(\mu \mathrm{m})\end{array}$ & $\begin{array}{c}\text { Sporangia } \\
\text { Length:Width } \\
\text { Ratio }\end{array}$ & $\begin{array}{l}\text { Chlamydospore } \\
\text { Diameter }(\mu \mathrm{m})\end{array}$ & $\begin{array}{c}\text { Oogonia } \\
\text { Diameter }(\mu \mathrm{m})\end{array}$ & $\begin{array}{c}\text { Oospore } \\
\text { Diameter }(\mu \mathrm{m})\end{array}$ & $\begin{array}{l}\text { Antheridia } \\
\text { Width }(\mu \mathrm{m})\end{array}$ \\
\hline \multirow{2}{*}{$\mathrm{MFG}^{\mathrm{b}}$} & 1 & $68.3 \pm 13.5 \mathrm{a}$ & $41.8 \pm 6.0 \mathrm{a}$ & $1.63 \pm 0.23 \mathrm{a}$ & $45.6 \pm 7.2 \mathrm{a}$ & $40.6 \pm 3.9 \mathrm{a}$ & $36.76 \pm 3.8 \mathrm{a}$ & $17.4 \pm 2.3 \mathrm{a}$ \\
\hline & 2 & $65.2 \pm 11.7 \quad b$ & $36.2 \pm 4.1 \quad b$ & $1.80 \pm 0.29 \quad b$ & $45.3 \pm 6.0 \mathrm{a}$ & $40.6 \pm 4.3 \mathrm{a}$ & $36.78 \pm 3.9 \mathrm{a}$ & $17.3 \pm 2.5 \mathrm{a}$ \\
\hline \multirow{2}{*}{$\begin{array}{l}\text { Isolate } \\
\text { Origin } \\
\text { (Latitude) }\end{array}$} & 37 to 39 & $69.2 \pm 12.7 \mathrm{a}$ & $39.6 \pm 6.1 \mathrm{a}$ & $1.76 \pm 0.28 \mathrm{a}$ & $46.5 \pm 5.9 \mathrm{a}$ & $41.28 \pm 4.10 \mathrm{a}$ & $37.4 \pm 4.0 \mathrm{a}$ & $17.4 \pm 2.5 \mathrm{a}$ \\
\hline & $\mathrm{N}$ of 39 & $65.0 \pm 12.3 b$ & $38.4 \pm 5.5 b$ & $1.70 \pm 0.27 \quad b$ & $45.0 \pm 7.0 \quad b$ & $40.05 \pm 4.05 \quad b$ & $36.3 \pm 3.7 \quad b$ & $17.2 \pm 2.3 \mathrm{a}$ \\
\hline \multirow{2}{*}{$\begin{array}{l}\text { Host Oak } \\
\text { Type }\end{array}$} & White & $67.2 \pm 12.9 \mathrm{a}$ & $39.5 \pm 5.7 \mathrm{a}$ & $1.71 \pm 0.28 \mathrm{a}$ & $45.0 \pm 6.9 \mathrm{a}$ & $40.5 \pm 4.1 \mathrm{a}$ & $36.7 \pm 4.0 \mathrm{a}$ & $17.3 \pm 2.1 \mathrm{a}$ \\
\hline & Red & $64.5 \pm 11.6 b$ & $37.0 \pm 5.1 \quad b$ & $1.75 \pm 0.27 \quad b$ & $46.3 \pm 6.1 \quad b$ & $40.6 \pm 4.2 \mathrm{a}$ & $36.7 \pm 3.7 \mathrm{a}$ & $17.6 \pm 3.0 \mathrm{a}$ \\
\hline \multirow{2}{*}{$\begin{array}{c}\text { Colony } \\
\text { Morphology }\end{array}$} & Rosaceous & $66.4 \pm 12.6 \mathrm{a}$ & $39.7 \pm 6.1 \mathrm{a}$ & $1.68 \pm 0.26 \mathrm{a}$ & $45.2 \pm 7.0 \mathrm{a}$ & $40.5 \pm 4.0 \mathrm{a}$ & $36.7 \pm 3.8 \mathrm{a}$ & $17.4 \pm 2.3 \mathrm{a}$ \\
\hline & Stellate & $67.1 \pm 12.8 \mathrm{a}$ & $37.1 \pm 4.6 \quad b$ & $1.81 \pm 0.30 \mathrm{a}$ & $46.0 \pm 5.5 \mathrm{a}$ & $40.7 \pm 4.3 \mathrm{a}$ & $36.9 \pm 3.9 \mathrm{a}$ & $17.2 \pm 2.6 \mathrm{a}$ \\
\hline
\end{tabular}

${ }^{\mathrm{a}}$ Means within a group followed by the same letter are not significantly different (Tukey-Kramer HSD).

${ }^{\mathrm{b}} \mathrm{MFG}=$ Microsatellite Fingerprint Group 


\subsection{Colony Growth Rate}

Colony diameter growth rates varied among isolates (Table 3). Average growth rate usually was fastest at $20^{\circ} \mathrm{C}$ and slowest at $32^{\circ} \mathrm{C}$. The fastest growth rate at any temperature was recorded with isolate $\mathrm{WV} 4 / 2$ at $20^{\circ} \mathrm{C}$. The slowest growth rate at $20^{\circ} \mathrm{C}$ was recorded with isolate IN $2 / 1$. The slowest recorded growth rate for $24^{\circ} \mathrm{C}$ was with isolate MD 1/4 and the fastest growth at this temperature was with isolate WV $4 / 2$. The slowest growth rate at $28^{\circ} \mathrm{C}$ was recorded with WVE-UF $13 / 1$ and the fastest was recorded with WV 3/1. The slowest growth rate at $32^{\circ} \mathrm{C}$ was recorded with WV-UF 5/3, which also was the slowest average growth rate recorded overall. The fastest growth at $32^{\circ} \mathrm{C}$ was recorded with isolate MD 2/1. No growth was observed for any isolate at $34^{\circ} \mathrm{C}$ or $37^{\circ} \mathrm{C}$.

Significant variations in growth rate were observed when isolates were grouped based on microsatellite fingerprints, geographic origin, oak host type, and colony morphology (Table 5). When grouped by microsatellite fingerprints, MFG1 isolates had significantly greater growth rates at $20^{\circ} \mathrm{C}\left(P<0.001, R^{2}=0.07\right)$ and $24^{\circ} \mathrm{C}\left(P<0.001, R^{2}=0.47\right)$ than MFG2 isolates. Conversely, MFG2 isolates grew significantly faster at $28^{\circ} \mathrm{C}\left(P<0.001, R^{2}=0.07\right)$ and $32^{\circ} \mathrm{C}$ $\left(P<0.001, R^{2}=0.25\right)$ than MFG1 isolates (Table 5). Isolates from between the $37^{\text {th }}$ and $39^{\text {th }}$ latitude had significantly greater growth rates at $20^{\circ} \mathrm{C}\left(P=0.006, R^{2}=0.04\right), 24^{\circ} \mathrm{C}(P=0.006$, $\left.R^{2}=0.04\right)$, and $28^{\circ} \mathrm{C}\left(P<0.01, R^{2}=0.04\right)$ than isolates from south of the $37^{\text {th }}$ parallel. There was no difference in growth rate at $32^{\circ} \mathrm{C}$ of isolate geographic origin groups (Table 5). Isolates recovered from the rhizosphere of the different host groups showed no significant differences 
Table 5. Mean colony diameter growth rates of isolates grouped by microsatellite fingerprint, isolate geographic origin, host oak type, and colony morphology.

\begin{tabular}{|c|c|c|c|c|c|}
\hline \multirow{2}{*}{$\begin{array}{l}\text { Isolate } \\
\text { Groups }\end{array}$} & \multirow{2}{*}{$\begin{array}{c}\text { Group } \\
\text { Categories }\end{array}$} & \multicolumn{4}{|c|}{ Colony Growth Rate $(\mathrm{mm} / \mathrm{day})^{\mathrm{a}}$} \\
\hline & & $20^{\circ} \mathrm{C}$ & $24^{\circ} \mathrm{C}$ & $28^{\circ} \mathrm{C}$ & $32^{\circ} \mathrm{C}$ \\
\hline \multirow{2}{*}{$\mathrm{MFG}^{\mathrm{b}}$} & 1 & $17.9 \pm 3.9 \mathrm{a}$ & $16.3 \pm 2.1 \mathrm{a}$ & $12.2 \pm 2.4 \mathrm{a}$ & $5.0 \pm 1.4 \mathrm{a}$ \\
\hline & 2 & $16.2 \pm 3.4 \quad b$ & $12.9 \pm 1.4 \quad b$ & $13.1 \pm 1.5 \quad b$ & $6.9 \pm 1.8 b$ \\
\hline \multirow{2}{*}{$\begin{array}{l}\text { Isolate } \\
\text { Origin } \\
\text { (Latitude) }\end{array}$} & 37 to 39 & $18.0 \pm 4.7 \mathrm{a}$ & $15.2 \pm 2.8 \mathrm{a}$ & $13.2 \pm 2.2 \mathrm{a}$ & $6.2 \pm 1.9 \mathrm{a}$ \\
\hline & $\mathrm{N}$ of 39 & $16.4 \pm 2.7 \quad b$ & $14.1 \pm 2.1 \quad \mathrm{~b}$ & $12.4 \pm 1.9 \quad \mathrm{~b}$ & $5.8 \pm 1.8 \mathrm{a}$ \\
\hline \multirow{2}{*}{ Oak Type } & White & $17.0 \pm 4.4 \mathrm{a}$ & $14.2 \pm 2.2 \mathrm{a}$ & $13.5 \pm 2.1 \mathrm{a}$ & $6.4 \pm 1.6 \mathrm{a}$ \\
\hline & Red & $16.8 \pm 3.6 \mathrm{a}$ & $14.6 \pm 2.3 \mathrm{a}$ & $12.0 \pm 1.7 \quad b$ & $6.1 \pm 1.9 \mathrm{a}$ \\
\hline \multirow{2}{*}{$\begin{array}{l}\text { Colony } \\
\text { Morphology }\end{array}$} & Rosaceous & $17.6 \pm 3.8 \mathrm{a}$ & $15.1 \pm 2.5 \mathrm{a}$ & $12.7 \pm 2.3 \mathrm{a}$ & $5.7 \pm 1.9 \mathrm{a}$ \\
\hline & Stellate & $15.7 \pm 3.2 b$ & $13.2 \pm 1.5 \mathrm{~b}$ & $12.7 \pm 1.2 \mathrm{a}$ & $6.6 \pm 1.6 \mathrm{~b}$ \\
\hline
\end{tabular}

in growth rate at $20^{\circ} \mathrm{C}, 24^{\circ} \mathrm{C}$, and $32^{\circ} \mathrm{C}$. Isolates from white oak soils had a significantly greater growth rate at $28^{\circ} \mathrm{C}$ than isolates from red oak hosts (Table 5). When growth rates of isolates with different colony morphologies were compared, isolates with a rosaceous colony pattern had significantly greater growth rates at $20^{\circ} \mathrm{C}\left(P=0.002, R^{2}=0.05\right)$ and $24^{\circ} \mathrm{C}\left(P<0.001, R^{2}=0.12\right)$ while stellate isolates had greater average growth rate at $32^{\circ} \mathrm{C}\left(P=0.004, R^{2}=0.04\right)$. There was no significant difference in growth rate of the colony morphology groups at $28^{\circ} \mathrm{C}$ (Table 5).

Growth rate trends also were observed that varied across the microsatellite fingerprint and colony morphology groups. One trend was the difference in the change in growth rate from one incubation temperature to the next among isolate groups. Growth rates of MFG1 isolates decreased as incubation temperatures increased from $24^{\circ} \mathrm{C}$ to $28^{\circ} \mathrm{C}$, while MFG2 growth rates 
stayed relatively the same (Table 5). This also was observed for isolates with different colony patterns. The rosaceous colonies had a mean reduction in diameter growth rate of $2.4 \mathrm{~mm} /$ day between $24^{\circ} \mathrm{C}$ and $28^{\circ} \mathrm{C}$. The stellate colonies were much less affected and only had a mean growth rate reduction of $0.5 \mathrm{~mm} /$ day between the $24^{\circ} \mathrm{C}$ and $28^{\circ} \mathrm{C}$ incubation temperatures. At $32^{\circ} \mathrm{C}$ growth rates of both microsatellite fingerprint groups decreased, but the growth rates of MFG1 isolates were more negatively affected than MFG2 isolates. This also was observed in isolates with different colony patterns where the decrease in growth rate from $28^{\circ}$ to $32^{\circ} \mathrm{C}$ was greater for isolates with the rosaceous colony pattern than for isolates with the stellate colony pattern. Additionally, the difference in mean diameter growth rate from the lowest to the highest incubation temperature was significantly greater $\left(P<0.0001, R^{2}=0.2\right)$ for MFG1 isolates (13 $\mathrm{mm} /$ day) than for MFG2 isolates ( $9 \mathrm{~mm} /$ day). The difference in mean diameter growth rate from the lowest to the highest incubation temperature was significantly greater $\left(P<0.0001, R^{2}=0.09\right)$ for isolates with rosaceous colony morphology $(12 \mathrm{~mm} /$ day $)$ than for isolates with stellate colony morphology $(9 \mathrm{~mm} / \mathrm{day})$. These trends were not observed to occur in the other two isolate groups where the isolates in each category of each isolate group behaved similarly with regards to growth rate. As incubation temperatures increased, growth rates of isolates in isolate geographic origin and host groups decreased

\subsection{Cluster Analysis of Phenotypic Characteristics}

A hierarchal cluster analysis was constructed using the variables of mean sporangia length, sporangia width, sporangia length:width ratio; chlamydospore, oogonia, and oospore diameters; 


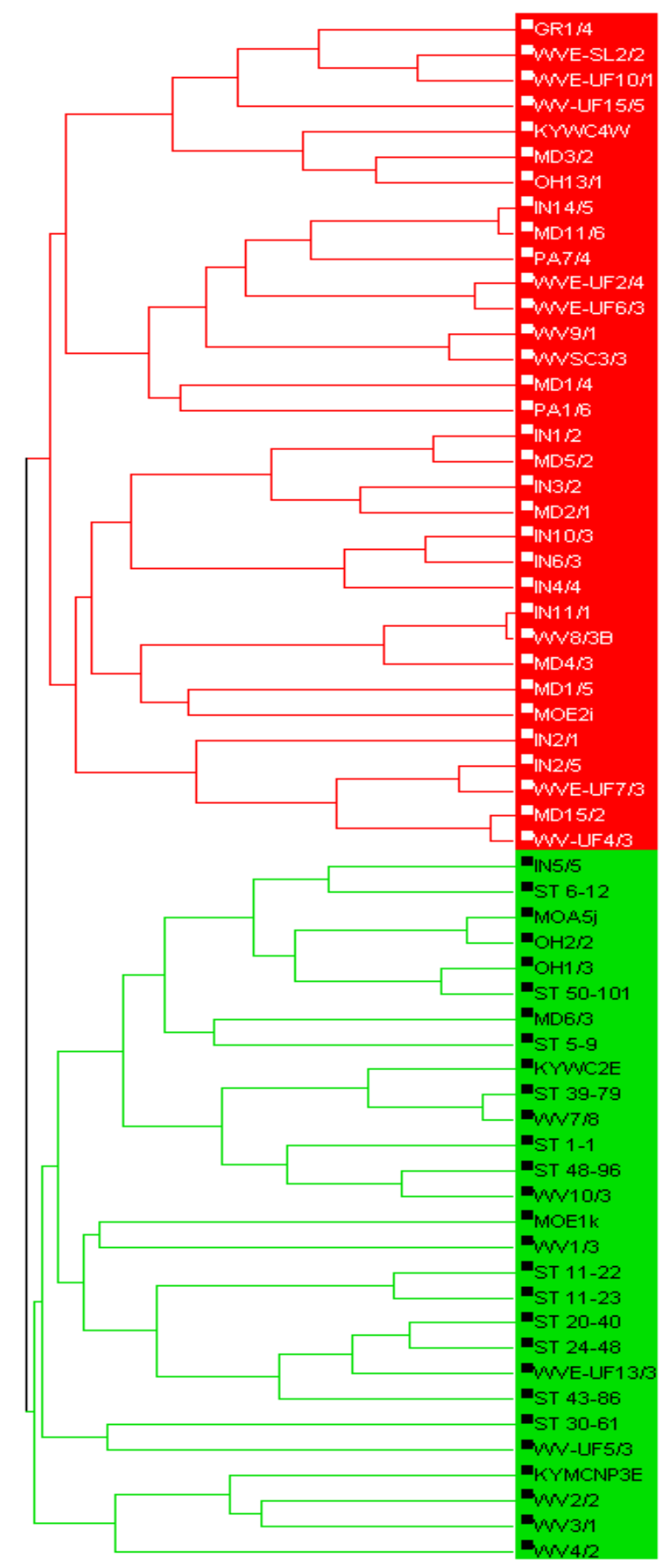

Figure 3. Cluster analysis of isolates based on tested phenotypic variables constructed using Ward's Method. Variables include sporangia length, width, and length:width ratio; chlamydospore, oogonia, and oospore diameters; antheridia width; colony morphology on PDA and colony growth rate at $20^{\circ} \mathrm{C}, 24^{\circ} \mathrm{C}, 28^{\circ} \mathrm{C}$, and $32^{\circ} \mathrm{C}$. Cluster 1 is highlighted in red and Cluster 2 is highlighted in green. 


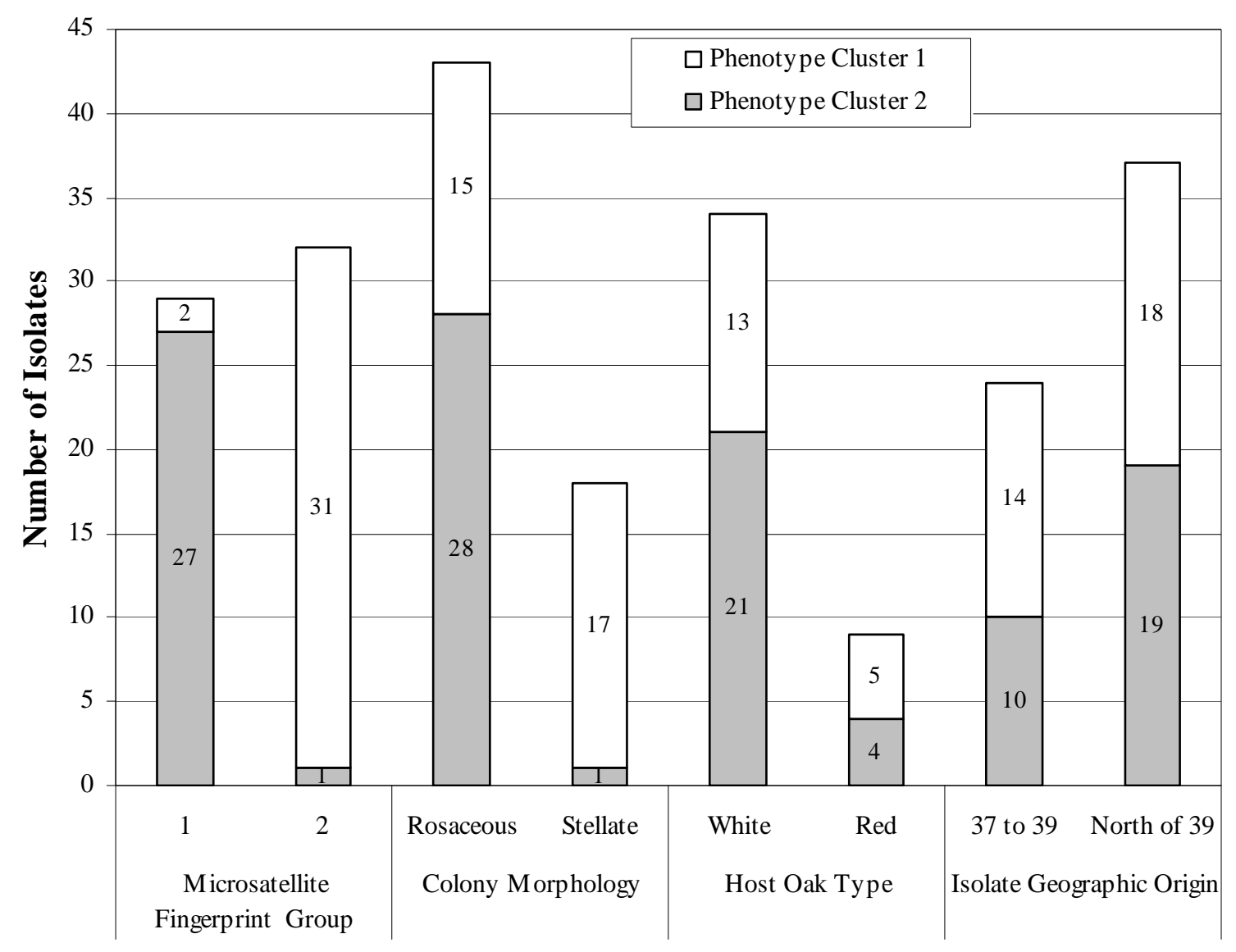

Isolate Groups

Figure 4. Number of isolates from each phenotypic cluster group (Figure 3) when grouped by microsatellite fingerprint, colony morphology, host oak type, and isolate geographic origin. (Fisher's Exact Test $\mathrm{P}<0.001, \mathrm{R}^{2}=0.65$ ).

antheridia width; and growth rates on CV8A at $20^{\circ} \mathrm{C}, 24^{\circ} \mathrm{C}, 28^{\circ} \mathrm{C}$, and $32^{\circ} \mathrm{C}$ for each isolate (Figure 3). The only isolates that did not cluster with isolates of the same MFG were KYWC4W, OH 13/1, and WV-UF 5/3. The analysis corresponded similar to microsatellite DNA fingerprint groups (Figure 4). Ninety three percent of the isolates in MFG1 grouped in phenotype cluster two and $97 \%$ of the isolates in MFG2 grouped in phenotype cluster one. Phenotype clusters and colony morphology also correlated. Ninety-four percent of the isolates with a stellate colony pattern grouped in phenotype cluster 1 (Fisher's Exact Test $P<0.001$, 
$\left.R^{2}=0.25\right)$. A significant relationship between isolate host oak type and phenotype cluster was measured. The majority of isolates from red oak rhizosphere soil $(78 \%)$ grouped in the phenotype cluster 1 and the remainder in cluster 2 . Conversely, $62 \%$ of the isolates from white oak soil grouped in phenotype cluster 1 and the remainder were in cluster 2 . These correlations were significant based on a 2 -tailed Fishers Exact Test $\left(P=0.009, R^{2}=0.11\right)$. The relationship between phenotype clusters and isolate geographic origin were not significant (Fisher's Exact Test $P=0.6)$.

\subsection{Relationship among groups defined by Microsatellite Fingerprint Patterns, Colony Morphology Geographic Origin, and Host.}

Isolates with a rosaceous colony pattern predominated MFG1 and the majority of the stellate isolates were in MFG2 (Figure 5). These relationships were significant (2-Tail Fisher's Exact Test $P=0.0002, \mathrm{R}^{2}=0.18$ ). Similarly, a greater number of isolates from white oak rhizosphere soil were in MFG1 and most of the isolates from red oak rhizosphere soil were in MFG2 (2-Tail Fisher's Exact Test $\left.P=0.009, R^{2}=0.11\right)($ Figure 5). Both geographic origin groups were composed of nearly equal numbers of isolates from each microsatellite fingerprint group (Figure $5)$.

When isolates were grouped based on colony morphology, isolates in the MFG1 more often formed rosaceous colonies (Fisher's Exact Test $P=0.0002, R^{2}=0.20$ ) (Figure 6). However, an equal number of isolates with rosaceous or stellate colony morphologies were in MFG2 (Figure 5). When colony morphology of isolates was compared across isolates from different oak types, isolates recovered from white oak rhizosphere soil more frequently formed the rosaceous 


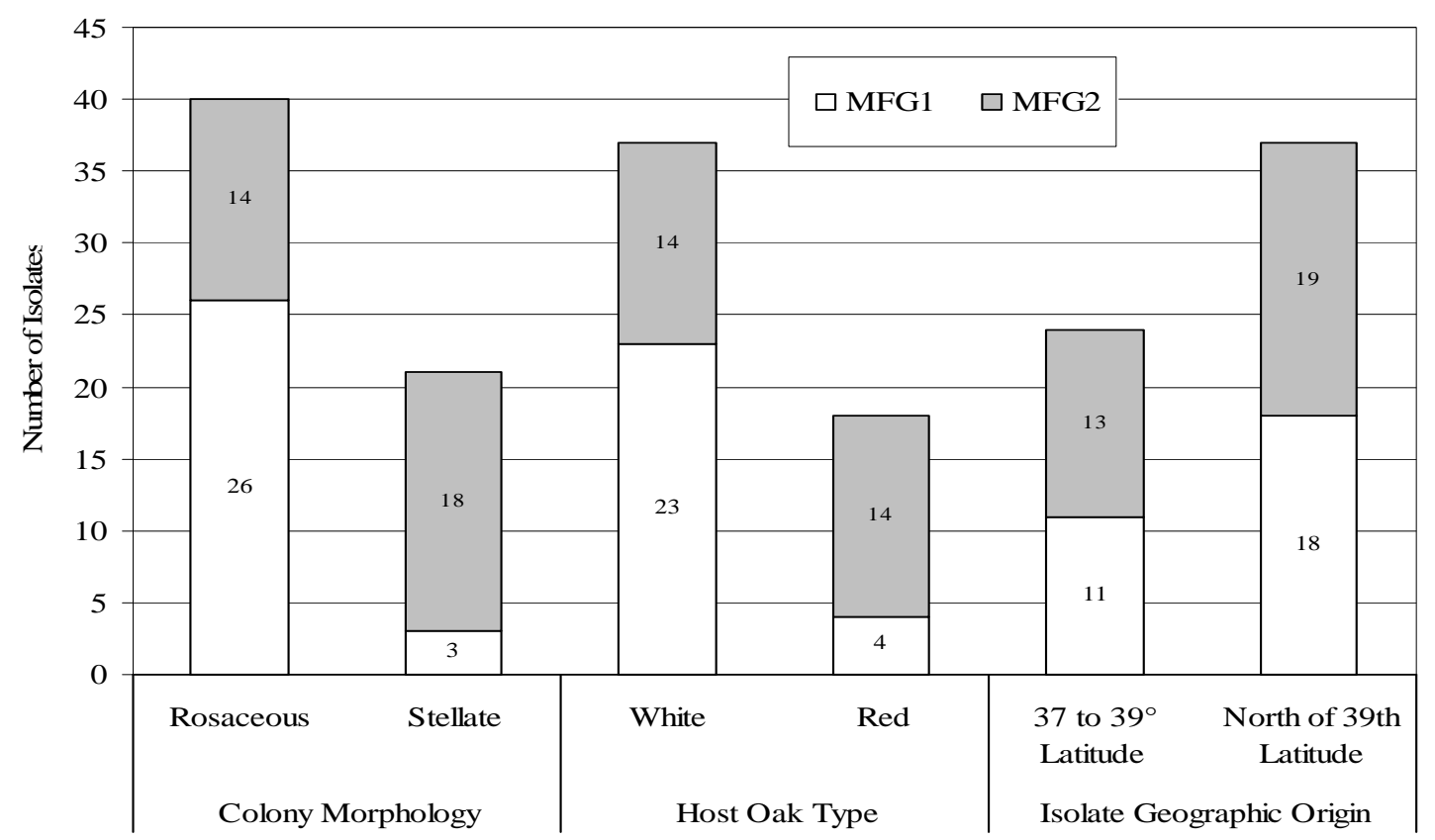

Figure 5. Number of isolates in microsatellite fingerprint group 1 (MFG1) and microsatellite fingerprint group 2 (MFG2) in each category of colony morphology, host oak type, and isolate geographic origin groups. Some isolates were not included in all of the groups due to missing host and/or origin data.

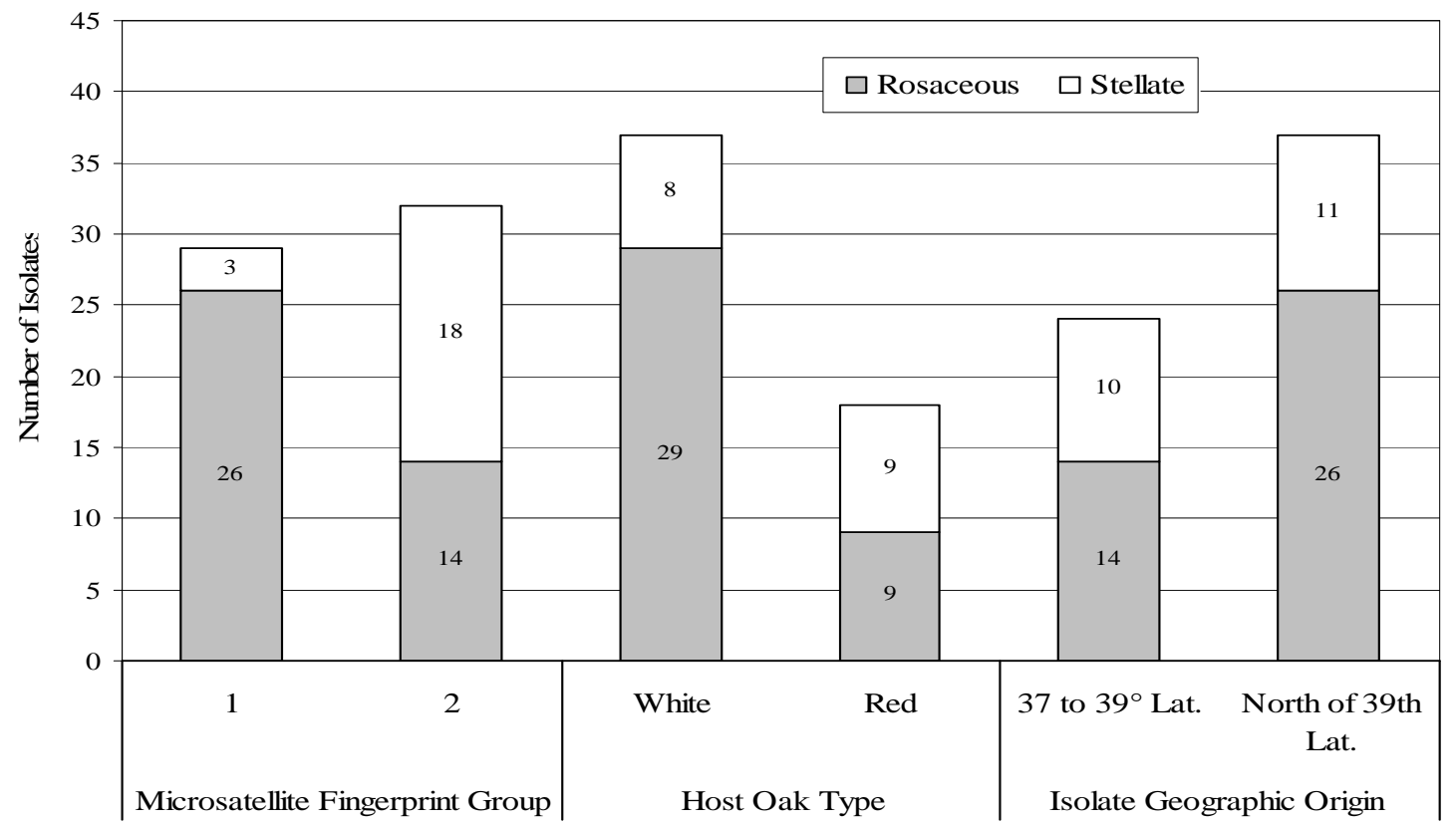

Figure 6. Number of isolates with rosaceous and stellate colony morphology in each category of microsatellite fingerprint, host oak type, and isolate geographic origin groups. Some isolates were not included in all of the groups due to missing host and/or origin data. 
colonies (Fisher's Exact Test $P=0.04, R^{2}=0.07$ ) (Figure 6). The relationship between the geographic origin of isolates and their colony morphology was not significant, although a greater number of isolates from sites north of the $39^{\text {th }}$ latitude formed rosaceous rather than stellate colonies (Figure 6).

\subsection{Pathogenic Variation}

No significant difference was detected among lesion sizes of all isolates (Table 6). All isolates except PA 1/6 and WVE-UF 5/3 produced significantly larger lesions on bark and cambial tissues of red oak logs than wounds inoculated with sterile agar plugs $(\mathrm{P}<0.05)($ Table 6$)$. Mean lesion areas of isolates grouped based on microsatellite fingerprint $(P=0.99)$, isolate geographic origin $(P=0.94)$, host oak type $(P=0.24)$, or colony morphology $(P=0.91)$ did not differ significantly (Figure 7). 
Table 6. Ranked lesion area resulting from inoculations of Phytophthora cinnamomi isolates on to red oak (Quercus rubra) logs.

\begin{tabular}{ll}
\hline \multicolumn{1}{c}{ Isolates } & $\begin{array}{c}\text { Mean Lesion } \\
\text { Area }(\mathrm{mm})^{*}\end{array}$ \\
\hline ST1-1 & $5616 \mathrm{a}$ \\
IN2/5 & $4326 \mathrm{a}$ \\
OH2/2 & $4364 \mathrm{a}$ \\
MOA5j & $4594 \mathrm{a}$ \\
PA7/4 & $3579 \mathrm{a}$ \\
KYMCNP3E & $3691 \mathrm{a}$ \\
MD2/1 & $3333 \mathrm{a}$ \\
IN6/3 & $3901 \mathrm{a}$ \\
MD6/3 & $3337 \mathrm{a}$ \\
WVE-UF13/3 & $3073 \mathrm{a}$ \\
IN1/2 & $3382 \mathrm{a}$ \\
WV10/3 & $3208 \mathrm{a}$ \\
IN5/5 & $2944 \mathrm{a}$ \\
ST43-86 & $3541 \mathrm{a}$ \\
ST11-22 & $3623 \mathrm{a}$ \\
MD15/2 & $2637 \mathrm{a}$ \\
WV2/2 & $2972 \mathrm{a}$ \\
KYWC2E & $2314 \mathrm{a}$ \\
WV8/3B & $2483 \mathrm{a}$ \\
WV-UF15/5 & $2284 \mathrm{a}$ \\
MOE2i & $1925 \mathrm{a}$ \\
PA1/6 & $2191 \mathrm{ab}$ \\
WV-UF5/3 & $1156 \mathrm{ab}$ \\
Control & $428 \mathrm{~b}$ \\
\hline letter are not significantly different (Tukey-Kramer HSD). \\
\end{tabular}




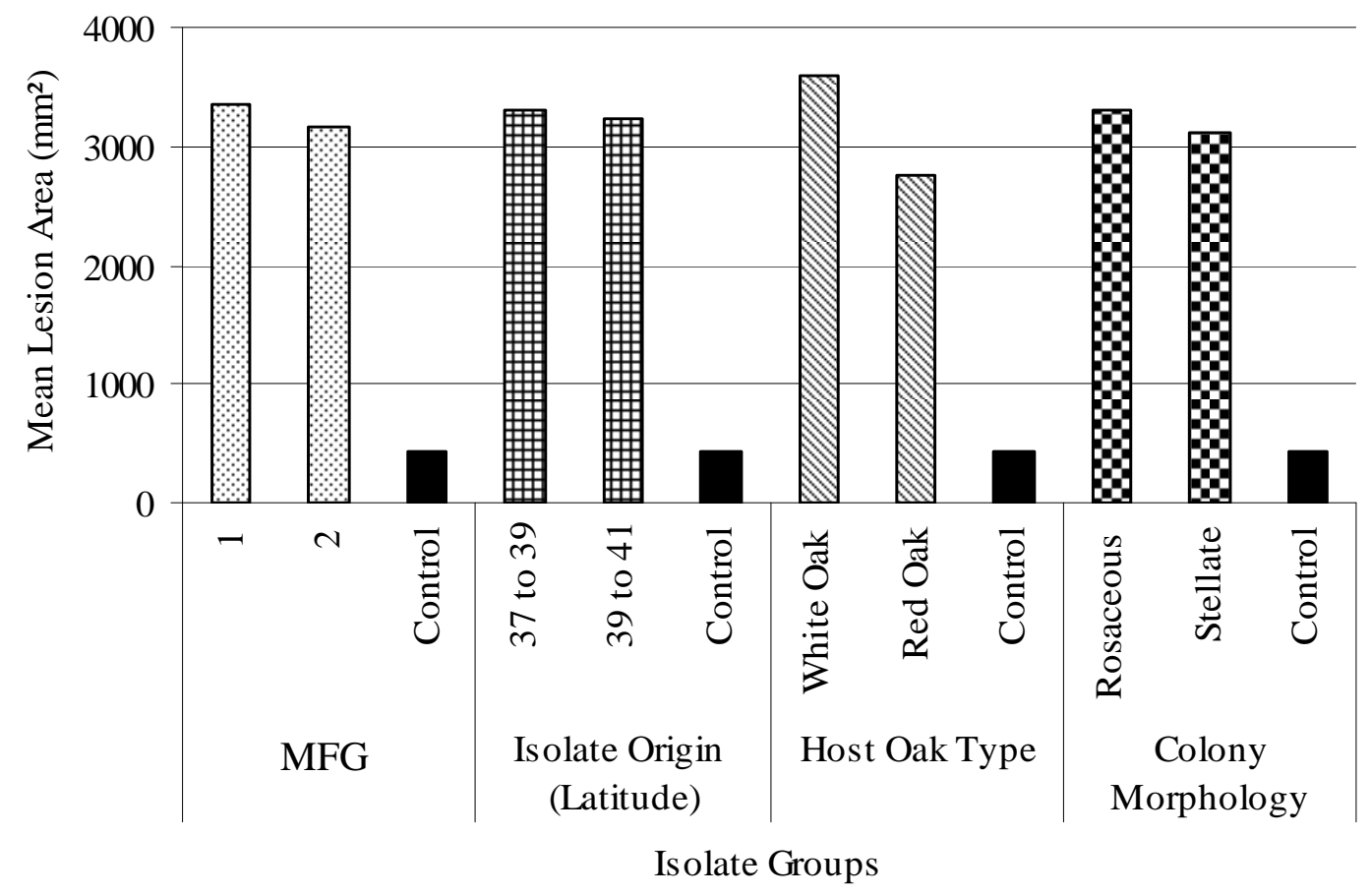

Figure 7. Comparison of mean lesion areas on red oak logs caused by Phytophthora cinnamomi isolates grouped by microsatellite fingerprint group (MFG), isolate geographic origin, host oak type, and colony morphology. Bars with a different pattern within each isolate group category are significantly different (Tukey-Kramer HSD). 


\section{Discussion}

The goal of this study was to investigate the phenotypic and genotypic characteristics of $P$. cinnamomi population originating from eastern US oak forest soils. These isolates were collected as part of a study to determine the species composition found in oak forest ecosystems. Their role in oak decline still remains to be explored and multiple questions still remain about their biology and impact. The work conducted provided insights on the characteristics of $P$. cinnamomi isolates from U.S. forests.

\subsection{Genetic Variation}

Microsatellite analysis of US P. cinnamomi isolates indicated low levels of genetic diversity among isolates collected from the study area. Isolates in this study were divided into two populations based on microsatellite fingerprint patterns (MFP) and the majority of isolates within each Microsatellite Fingerprint Group (MFG) were identical at loci e16, g13 and d39. This low level of genetic diversity has been shown to occur in other $P$. cinnamomi populations. The most extensive study of $P$. cinnamomi population genetics using the same molecular markers was conducted by Dobrowolski et al. (2003). The authors showed that isolates from Australia also had very low levels of genetic diversity. Genetic analysis of U.S. P. cinnamomi isolates from South Carolina using amplified fragments polymorphisms (AFLP) provided additional evidence of low genetic variability in P. cinnamomi from the US (Duan, Riley, and Jeffers 2008). Dobrowolski et al. (2003) and Huberli et al. (2001) showed that the majority of A2 P. cinnamomi isolates in Australia could be divided into two groups using the same microsatellite markers which divided US isolates into the two groups identified in this study. Additionally, 
some of the allele fragment lengths are shared between the groups established by Dobrowolski and the US MFGs.

Comparisons of microsatellite fingerprints of US isolates to the fingerprints of P. cinnamomi isolates from Dobrowolski et al. (2003) and Huberli et al. (2001) indicated similarities in $P$. cinnamomi isolates from different continents (Table 7). Isolates of MFG1 were identical to the predominant fingerprint pattern of Dobrowolski's Australian A2 type 1 isolates at the e16 locus (169/171) and have the same marker size on one allele at locus d39 (122). The other d39 allele of the US MFG1 isolates matches one allele at the d39 locus (120) of the Australian A1 type $1 P$. cinnamomi isolates. Locus $\mathrm{g} 10$ of US MFG1 isolates have markers not found in the three predominant genotypes identified by Dobrowolski et al. (2003). The 120 base pair marker consistently found in the US MFG1 isolates also was present in an A1 P. cinnamomi isolate from the western US included in the Dobrowolski et al. (2003) analysis. The US MFG2 isolates appear to have originated from a greater number of $P$. cinnamomi isolates characterized by Dobrowolski et al. (2003). The markers at e16 of US MFG2 match those of the Australian A2 type 2 (163) and markers found in P. cinnamomi isolates from Papua New Guinea (161). The d39 locus of US MFG2 isolates matches markers found in both the d39 locus of Australian A1 type 1 isolates and the $\mathrm{d} 39$ locus of Australian A2 type 1 isolates (Dobrowolski et al. 2003). The markers of the g10 locus of MFG2 do not match any of the predominant genotypes found in Australia. The most frequent markers found in the US isolates were 115 and 117 base pairs in length. These markers could be the result of nucleotide deletion on both alleles at the g10 locus of the Australian P. cinnamomi A1 type 1 (116 and 118) or nucleotide insertion on both alleles at the g10 locus of the Australian P. cinnamomi A2 type 2 (114 and 116). The less frequently 
Table 7. Most commonly observed allele sizes at microsatellite loci d39, e16 and g10 of $P$. cinnamomi isolates from Australia, Papua New Guinea, and the eastern United States.

\section{Common DNA Fragment Lengths of}

Microsatellite Locus Alleles

\begin{tabular}{ccccc} 
P. cinnamomi & & \multicolumn{3}{c}{ (nucleotides) } \\
\cline { 3 - 5 } Microsatellite Group $^{\text {MFG1 }}{ }^{\mathrm{b}}$ & Isolate Origin $^{\mathrm{c}}$ & Locus d39 & Locus e16 & Locus g10 \\
\hline MFG2 $^{\mathrm{b}}$ & US & $120 / 122$ & $169 / 171$ & $117 / 120$ \\
A1 type $1^{\mathrm{a}}$ & US & $122 / 124$ & $161 / 163$ & $115 / 117$ \\
A2 type $1^{\mathrm{a}}$ & AUS, PNG & $120 / 124$ & $169 / 169$ & $116 / 118$ \\
A2 type $2^{\text {a }}$ & AUS, PNG & $122 / 136$ & $169 / 171$ & $118 / 154$ \\
\hline
\end{tabular}

${ }^{a}$ As described by Dobrowolski et al. (2003)

${ }^{\mathrm{b}} P$. cinnamomi isolates from eastern US forest soils

${ }^{c}$ AUS=Australia, $\mathrm{PNG}=$ Papua New Guinea, US=United States

observed markers at the g10 locus for the MFG2, 116 and 114, also are found at the g10 locus of the Australian A1 type 1 (116 only), Australian A2 type 2 (both) and some of the other world isolates including isolates from Papua New Guinea and the US (Dobrowolski et al. 2003). Other P. cinnamomi populations distributed worldwide also are represented predominantly by two genotypes. Linde et al. (1999) found South African A2 mating type P. cinnamomi isolates were one of two RFLP genotypes. They also determined that genotypes of $P$. cinnamomi isolates from Australia and Papua New Guinea were identical to those of the South African isolates. Comparison of other populations to Australia and US P. cinnamomi microsatellite groups is difficult due to the variety of molecular methods used to distinguish the different genotypes (Linde et al. 1999, Huberli et al. 2001, Dobrowolski et al. 2003). All methods previously used provide reliable data but unless isolates from multiple populations are included as controls, genetic similarities among all dual A2 populations is difficult to prove. The dissimilarities between microsatellite fingerprint patterns of US P. cinnamomi isolates and those studied by Dobrowolski et al. (2003) suggests that while the $P$. cinnamomi population from our study can be divided into two groups based on microsatellite fingerprints, these populations are not direct clonal descendents of the predominant $P$. cinnamomi genotypes described by Dobrowolski et al. 
(2003) and Huberli et al. (2001). This probably holds true for A2 P. cinnamomi isolates from other parts of the world. Conversely, microsatellite marker similarities among isolates from the US, Australia and Papua New Guinea does suggest that they all have a common ancestor, possibly of Austral-Asian origin. Microsatellite fingerprint characteristics of the US $P$. cinnamomi isolates give clues to possible origins of these two lineages. The shared allele of the two MFGs at locus d39 suggests that all US isolates had a common ancestor. The absence of the A1 mating type reduces the likelihood of sexual recombination with A2 isolates as a source of the shared allele. In Australia, where two mating types were found in close proximity, evidence of sexual recombination could not be found (Dobrowolski et al. 2003). Variation in microsatellite fingerprints of Australian isolates was attributed to mitotic recombination. However, the data suggest that the shared allele in the US P. cinnamomi isolates most likely did not arise from such mitotic recombination or through genetic exchange between two individuals of different fingerprint groups. If mitotic recombination or exchange between isolates from each MFG had occurred, variability in fingerprint patterns of recovered isolates would have been greater. Presumably, if mitotic recombination were occurring, there would have been isolates that were homozygous at $\mathrm{d} 39$ and there would have been greater marker variability at locus g13 because the two loci are linked (Dobrowolski et al. 2002). Isolates from each MFG were found coexisting at two of the sites from which P. cinnamomi was isolated. One site was the West Virginia University forest, which was intensively sampled. The data from this site as well as data including all sites demonstrate that isolates in each MFG are heterozygous at both d39 and g13 and that neither group shares alleles at g13. Additionally, the consistency of the MFG1 and MFG2 across a very large sample area suggests that these genotypes were formed prior to the establishment of these populations. Thus, the common allele probably was the result of sexual 
recombination with a $P$. cinnamomi A1 mating type isolate before these populations were established at the sites from which isolates were collected and possibly prior to their introduction to North America.

Determining the origin of the US P. cinnamomi populations will require further investigation of $P$. cinnamomi present in the US along with analysis of $P$. cinnamomi isolates from other continents using a standardized method such as analysis of the same microsatellite markers or DNA sequencing. The microsatellite markers developed by Dobrowolski et al. (2003) can consistently differentiate genetic differences among $P$. cinnamomi populations, even those that are geographically distant from the populations used to develop the markers.

\subsection{Phenotypic Variation}

The variations in phenotypic characteristics observed in the P. cinnamomi populations studied here were consistent with variations described by other researchers. Average sporangia size is somewhat larger than that first described by Rands (1922), but other detailed descriptions have reported similar ranges and averages for sporangia length, width and length-width ratio (Royal and Hickman 1964, Ho and Zentmyer 1977, Gerrettson-Cornell 1983, Gallegly and Hong 2008). The largest sporangium recorded in this study (14 $\mu \mathrm{m}$ longer and $15 \mu \mathrm{m}$ wider) appears to be the largest recorded for $P$. cinnamomi when compared to the largest sporangia measured by Royle and Hickman (1964). Average chlamydospore diameter and range of variation among isolates in this study were slightly greater than those described by Rands (1922). The dimensions of antheridia, oogonia, and oospores were within maximum and minimum measurement ranges and within the range of means described previously (Royal and Hickman 1964, Ann and Ko 1985, 
Garretson-Cornell 1989, Huberli et al. 2001, Gallegly and Hong 2008). Likewise, colony morphology did not deviate greatly from previous descriptions (Huberli et al. 2001, Zentmyer 1980). Growth rates were slightly higher than reported by Huberli et al. (2001) but were similar to that of the $P$. cinnamomi type culture (Zentmyer 1980).

\subsection{Relationship of Phenotype, Microsatellite Fingerprint, Host and Geographic Origin}

This is the first study where large numbers of $P$. cinnamomi isolates from the US compared interspecific phenotypic and genotypic characteristics relative to geographic and host plant origin. Asexual and sexual spore features differed most with regard to geographic origin suggesting a geographical effect on expression of phenotype. Huberli et al. (2001) also observed differences in sporangia dimensions of isolates from different study sites. Because of considerable variation in sporangia size, however, the reliability of this trait to identify subspecies is limited (Zentmyer 1980). In this study, chlamydospore, oogonia, and oospore diameters also differed significantly between isolates from different latitude zones, but all means still fell within the ranges reported in past descriptions (e.g. Zentmyer 1980). Sporangia dimensions were significantly different when isolates were grouped and compared based on host, MFP and colony morphology. Chlamydospore dimensions of isolates grouped by host type also were significantly different. The level of significance $(P)$ when comparing spore means from different isolate groupings was relatively similar and the $\mathrm{R}^{2}$ of all spore dimensions comparisons in relation to MFP, origin, host, or colony morphology was small. Sporangia, chlamydospores, oospores, oogonia, and antheridia dimensions were weakly correlated to MFP, geographic origin, host, or colony morphology because standard deviations was high for all means and often overlapped. The large variation in spore characteristics observed for each isolate further 
supports that the variation of spore dimensions between isolate groups is explained by the variation inherent in the species and not by the factors used to separate the isolates in this study.

Colony morphology of these US P. cinnamomi isolates could not be predicted by genotype, host, or geographic origin, even though each MFG tended to exhibit one colony morphology more frequently than the other. Varying results on the linkage between genotype groups and colony morphology have been reported by others. Colony morphology of Australian P. cinnamomi isolates also grouped with a particular genotype (Dobrowolski et al. 2003). In contrast, colony morphology of Australian A2 type 1 isolates from a single site varied considerably (Huberli et al. 2001). Environment may have contributed to this variation, since colony morphology of some isolates changed with incubation temperature. Despite some consistency of correlation between colony morphology and MFP, evidence also indicates colony morphology of P. cinnamomi isolates depends on other factors, so that colony morphology alone is not diagnostic of genotype differences.

The relationship between isolate colony morphology and host was only evident with isolates recovered from soil around white oaks. This result may be attributed in part to the grouping of these isolates in the MFG1 and predominant rosaceous colony pattern. Conversely, isolates from sites north of the $39^{\text {th }}$ latitude grouped with similar frequency in each MFG, but isolates from northern sites had a higher frequency of rosaceous colonies. Possibly, isolates with this colony morphology have a survivability advantage at lower temperatures, or they are more sensitive to higher temperatures. The latter hypothesis is supported by growth rate data where isolates with 
rosaceous colony patterns were less tolerant of temperature increases than isolates with stellate colony morphologies.

\subsection{Pathogenic Variation}

One value of discriminating among subgroups of a particular species of a plant pathogen, be it by their physical characteristics or their genetics, is to determine if these variations translate into variations in each group's ability to cause disease and whether such variation might influence pathogenicity. The $P$. cinnamomi isolates studied in this work varied phenotypically and genetically. The differences in MFP or phenotype of isolates do not appear to translate into pathogenic variation when inoculated to red oak. This does not rule out the possibility that $P$. cinnamomi isolates belonging to each MFG do not differ in their pathogenic potential to hosts other than red oak. Variation in pathogenicity of $P$. cinnamomi on other oak and other tree genera has been reported, although the genetics of the isolates were not characterized (Crandle $e t$ al. 1945, Jordan and Tainter 1996, Robin and Desprez-Loustau 1998). Linde et al. (1999) reported correlations between $P$. cinnamomi isolate multilocus isozyme genotypes and the level of pathogenicity in eucalyptus, suggesting genotype variation may indicate pathogenic variability. Inoculation data from the present study, however, suggest that microsatellite fingerprint groups do not differ in pathogenicity. Additional pathogenicity tests on other $P$. cinnamomi hosts from different genera may differentiate pathogenicity among the different MFG found in the US. Balci et al. (2008) showed that one $P$. cinnamomi isolate from eastern forest soils varied in pathogenicity when inoculated into the stems of four different oak species. An isolate from the same site was used in this study and it was found to belong to the MFG2. An isolate belonging to MFG1 may therefore exhibit similar variation. Whether or not the variation 
would be consistent with that of MFG2 isolates is unknown. The different P. cinnamomi microsatellite fingerprint groups may even have similar pathogenicities on oaks but each fingerprint group may react differently to other known hosts. Knowing the pathogenicity of these MFG on a wide range of $P$. cinnamomi hosts would be useful in developing plant cultivars resistant to $P$. cinnamomi. If different microsatellite fingerprint groups did turn out to have different pathogenicities on different hosts, the microsatellite markers would be useful in distinguishing which isolates were pathogenic on which hosts.

The presence of this fungus-like organism in ecosystems across the globe and the diversity of its hosts is testament to the versatility of this pathogen. This study has shown that the pathogenic versatility and cosmopolitan nature of $P$. cinnamomi arise from a rather discrete set of characters that have changed little despite its spread across the globe. Questions still remain about the impact of $P$. cinnamomi on health of northeastern US forests and why $P$. cinnamomi is not having a greater impact on tree species known to be susceptible to infection. The extensive phenotypic evaluation would suggest that physical differences are not vastly different among $P$. cinnamomi isolates and the same can be said for genetic variation. This leads one to believe that there are other external factors influencing the ability of the P. cinnamomi populations in eastern forests to cause disease. One such factor could be climate. As previously stated, the northern limit of $P$. cinnamomi in the eastern US is around the $40^{\text {th }}$ latitude. Isolates were collected from regions with an average annual minimum temperature range of $-12^{\circ} \mathrm{C}$ to $-23^{\circ} \mathrm{C}$ (USDA Plant Hardiness Zone). These low winter temperatures probably prevent a build up of inoculum (Brasier and Scott 1994), which may be the reason why a greater disease impact is not seen. Balci et al. (2008) demonstrated in field inoculation experiments that lesions development of 
stem inoculated oak seedlings varied between spring and fall inoculations. When inoculated in the fall, lesion development was decreased, probably due to lower temperatures. Even if natural stem infections were to occur, winter temperatures would slow the progression of the disease possibly allowing the tree to overcome the infection. These are important considerations when looking to the future of these forests. While P. cinnamomi was not observed causing above ground infections in the northeast-central US, decreased periods of temperatures that limit $P$. cinnamomi growth in the soil could result in increased $P$. cinnamomi inoculum, leading to more root infections. Warmer or shorter winters also could result in the progression of $P$. cinnamomi from the roots into the main stem of trees instead of being limited to the roots (Balci et al. 2008). Increasing temperatures could lead to an increase incidence of drought, thus weakening trees, leaving them more susceptible to P. cinnamomi infection (Brasier and Scott 1994).

Phytophthora cinnamomi has already been linked to white oak decline in southern Ohio (Balci et al. 2009) and could contribute to further decline or outright disease could be more commonplace if warming trends continue. 


\section{Literature Cited}

Ann, P. J. and Ko, W. H. 1985. Variants of Phytophthora cinnamomi extend the known limits of the species. Mycologia 77: 946-950.

Balci, Y., Balci, S., Eggers, J., MacDonald, W. L., Juzwik, J., Long, R., and Gottschalk, K. W. 2007. Phytophthora species associated with forest soils in the eastern and north central U.S. oak ecosystems. Plant Dis. 91: 705-710.

Balci, Y., Balci, S., MacDonald, W. L., and Gottschalk, K. W. 2008. Relative susceptibility of oaks to seven species of Phytophthora isolated from oak forest soils. For. Path. 38: 394-409.

Balci Y., Long R.P., Mansfield M., Balser D., MacDonald, W. L. (2009). Involvement of Phytophthora species in white oak (Q. alba) decline in southern Ohio. Forest Pathology, in press. doi: 10.1111/j.1439-0329.2009.00617.x

Balci, Y. and Halmschlager, E. 2003a. Phytophthora species in oak ecosystems in Turkey and their association with declining oak trees. Plant Pathology 52: 694-702.

Balci, Y. and Halmschlager, E. 2003b. Incidence of Phytophthora species in oak forests in Austria and their possible involvement in oak decline. For. Path. 33: 157-174.

Benson, D. M. and Grand, L. F. 2000. Incidence of Phytophthora root rot of Fraser fir in North Carolina and sensitivity of isolates of Phytophthora cinnamomi to metalaxyl. Plant Dis. 84: 661664.

Bernard, E. L. 2006. Some oak maladies of interest. Southwide and Northeast Forest Disease Workshop. Davis, West Virginia June 20-22. Abstract.

Bhat, R. G., Colowit, P. M., Tai, T. H., Aradhya, M. K., and Browne, G. T. 2006. Genetic and pathogenic variation in Phytophthora cactorum affecting fruit and nut crops in California. Plant Dis. 90: 161-169.

Braiser, C. M. and Scott, J. K. 1994. European oak declines and global warming: a theoretical assessment with special reference to the activity of Phytophthora cinnamomi. EPPO Bulletin 24: 221-232.

Caetano, P., Ávila, A., Sánchez, M.E., Trapero, A., and Coelho, A.C. 2007. Phytophthora cinnamomi populations on Quercus forests from Spain and Portugal. Fourth IUFRO Working Party Meeting on Phytophthoras in Forests and Natural Ecosystems. Monterey, CA, August 2631.

Chen, D. and Zentmyer, G. A. 1970. Production of sporangia by Phytophthora cinnamomi in axenic culture. Mycologia 62: 397-401. 
Cohen, S., Allasia, V., Vernard, P., Notter, S., Vernière, C. and Panabières, F. 2003. Intraspecific variation in Phytophthora citrophthora from citrus trees in Eastern Corsica. Eur. J. of Plant Pathol. 109: 791-805.

Cooke, D. E. L., Jung, T., Williams, N. A., Schubert, R. Oßwald, W., and Duncan, J. M. 2005. Genetic diversity of European populations of the oak fine-root pathogen Phytophthora quercina. For. Path. 35: 57-70.

Crandall, B. S., Gravatt, G. F., and Milburn Ryan, M. 1945. Root disease of Castanea species and some coniferous and broadleaf nursery stocks, caused by Phytophthora cinnamomi. Phytopathology 35: 162-180.

Dobrowolski, M. P., Tommerup, I. C., Blakeman, H. D., and O’Brien, P. A. 2002. NonMendelian inheritance revealed in a genetic analysis of sexual progeny of Phytophthora cinnamomi with microsatellite markers. Fungal Genetics and Biology 35: 197-212.

Dobrowolski, M. P., Tommerup, I. C., Shearer, B. L., and O’Brien, P. A. 2003. Three clonal lineages of Phytophthora cinnamomi in Australia revealed by microsatellites. Phytopathology 93: 695-704.

Duan, C. -H., Riley, M. B. and Jeffers, S. N. 2008. Characterization of Phytophthora cinnamomi populations from ornamental plants in South Carolina, USA, Archives of Phytopathology and Plant Protection 41: 14-30.

Eikemo, H., Klemsdal, S. S., Riisberg, I., Bonants, P., Stensvand, A., and Tronsmo, A. M. 2004. Genetic variation between Phytophthora cactorum isolates differing in their ability to cause crown rot in strawberry. Mycol. Res. 108: 317-324.

Erwin, D. C. and Ribeiro, O. K. Phytophthora cinnamomi Rands (1922) var. cinnamomi in Phytophthora Diseases Worldwide. APS Press, St. Paul, MN. 269-280.

Gallegly, M. E. and Hong, C. 2008. Phytophthora: Identifying Species by Morphology and DNA Fingerprints. APS Press, St. Paul, MN.

Garbelotto, M. and Huberli, D. 2006. First report on an infestation of Phytophthora cinnamomi in natural oak woodlands of California and its differential impact on two native oak species. Plant Disease 90: 685.

Gerrettson-Cornel, L. 1983. A compendium of the morphology of Phytophthora cinnamomi Rands from Australia. Acta. Bot. Hung. 29:91-105.

Hamm, P. B. and Hansen, E. M. 1982. Pathogenicity of Phytophthora species to Pacific Northwest conifers. Eur. J. For. Path. 12: 167-174.

Hantula, J., Lilja, A., and Parikka, P. 1997. Genetic variation and host specificity of Phytophthora cactorum isolated in Europe. Mycol. Res. 101: 565-572. 
Hantula, J., Lilja, A., Nuorteva, H., Parikka, P. and Werres, S. 2000. Pathogenicity, morphology and genetic variation of Phytophthora cactorum from strawberry, apple, rhododendron, and silver birch. Mycol. Res. 104: 1062-1068.

Hardham, A. R. 2005. Phytophthora cinnamomi. Molecular Plant Pathology 6: 589-604.

Hawang, S. C., Ko, W. H., and Aragaki, M. 1975. A simplified method for sporangial production by Phytophthora cinnamomi. Mycologia 67: 1233-1234.

Ho, H. H. and Zentmyer, G. A. 1977. Morphology of Phytophthora cinnamomi. Mycologia 69: 701-713.

Huang, H., Jeffers, S. N., Layne, D. R., and Schnabel, G. 2004. AFLP analysis of Phytophthora cactorum isolates from strawberry and other hosts: Implications for identifying the primary source of inoculum. Plant Dis. 88: 714-720.

Huberli, D., Tommerup, I. C., Dobrowolski, M. P., Calver, M. C., and Hardy, G. E. St. J. 2001. Phenotypic variation in a clonal lineage of two Phytophthora cinnamomi populations from Western Australia. Mycol. Research 105: 1053-1064.

Huberli, D., Tommerup, I. C., and Hardy, G. E. St J. 1997. The role of paragynous and amphigynous antheridia in sexual reproduction of Phytophthora cinnamomi. Mycol. Research 101: 1383-1388.

Jönsson, U., Jung, T., Sonesson, K., and Rosengren, U. 2005. Relationships between health of Quercus robur, occurrence of Phytophthora species and site conditions in southern Sweden. Plant Pathology 54: 502-511.

Jordan, A. P. and Tainter, A. P. Susceptibility of southern Appalachian oaks to Phytophthora cinnamomi. Castanea 61: 348-355.

Jung, T., Blaschke, H., and Oßwald, W. Involvement of soilborne Phytophthora species in Central European oak decline and the effect of site factors on the disease. Plant Pathology 49: 706-718.

Kenerley, C. M. and Bruck, R. I. 1983. Overwintering and survival of Phytophthora cinnamomi in Fraser fir and cover cropped nursery beds in North Carolina. Phytopathology 73: 1643-1647.

Kenerley, C. M., Papke, K., and Bruck, R. I. 1984. Effect of flooding on development of Phytophthora root rot in Fraser fir seedlings. Phytopathology 74: 401-404.

Lasker, B. A. and Ran, Y. 2004. Analysis of polymorphic microsatellite markers for typing Penicillium marneffei isolates. Journal of Clinical Microbiology 42: 1483-1490. 
Linde, C., Drenth, A., Kemp, G. H. J., Wingfield, M. J., and von Broembsen, S. L. 1997. Population structure of Phytophthora cinnamomi in South Africa. Phytopathology 87: 822-827.

Linde, C., Drenth, A., and Wingfield, M. J. 1999. Gene and genotypic diversity of Phytophthora cinnamomi in South Africa and Australia revealed by DNA polymorphisms. Eur. J. of Plant Pathol. 105: 667-680.

Linde, C., Soo, S. H., and Drenth, A. 2001. Sexual recombination in Phytophthora cinnamomi in vitro and aggressiveness of single-oospore progeny to Eucalyptus. Plant Pathol. 50: 97-102.

Mircetich, S. M., Campbell, R. N., and Matheron, M. E. 1977. Phytophthora trunk canker of coast live oak and cork oak trees in California. Plant Dis. Reporter 61: 66-70.

Old, K. M., Dudzinski, M. J., and Bell, J. C. 1988. Isozyme variability in field populations of Phytophthora cinnamomi in Australia. Australian Journal of Botany 36: 355-360.

Old, K. M., Moran, G. F., and Bell, J. C. 1984. Isozyme variability among isolates of Phytophthora cinnamomi from Australia and Papua New Guinea. Canadian Journal of Botany 62: 2016-2022.

Oak, S. W. and Tainter, F. H. 1988. Risk prediction of loblolly pine decline on littleleaf disease sites in South Carolina. Plant Disease 72: 289-293.

Pratt, R. G., Roth, L. F., Hansen, E. M., and Ostrofsky, W.D. 1976. Identity and pathogenicity of species of Phytophthora causing root rot of Douglas-fir in the Pacific northwest. Phytopathology 66: 710-714.

Rands, R. D. 1922. Streepkanker van Kaneel, veroorzaakt door Phytophthora cinnamomi n. sp. (Stripe canker of cinnamon caused by Phytophthora cinnamomi n. sp.). Meded. Inst. Plantenziekten 54. 41 pp. (In Dutch).

Rizzo, D. M., Garbelotto, M., Davidson, J. M., Slaughter, G. W., and Koike, S. T. 2002. Phytophthora ramorum as the cause of extensive mortality of Quercus spp. and Lithocarpus densiflorus in California. Plant Disease 86: 205-214.

Robin, C. and Desprez-Loustau, M. -L. 1998. Testing variability in pathogenicity of Phytophthora cinnamomi. European Journal of Plant Pathology 104: 465-475.

Robin C, Desprez-Loustau ML, Capron G, Delatour C, 1998. First record of Phytophthora cinnamomi on cork and holm oaks in France and evidence of pathogenicity. Annales Des Sciences Forestière 55: 869-883.

Robin, C., Capron, G., and Desprez-Loustau, M. -L. 2001. Root infection by Phytophthora cinnamomi in seedlings of three oak species. Plant Pathology 50: 708-716. 
Royal, D. J. and Hickman, C. J. 1964. Observations on Phytophthora cinnamomi. Can. J. Bot. 42: 311-318.

Shepherd, C. J. and Pratt, B. H. 1974. Temperature-growth relations and genetic diversity of A2 mating-type isolates of Phytophthora cinnamomi in Australia. Australian Journal of Botany 22: 231-249.

Tainter, F. H., O’Brien, J. G., Hernandez, A., Orozoco, F., and Rebolledo, O. 2000. Phytophthora cinnamomi as a cause of oak mortality in the state of Colima, Mexico. Plant Disease 84: 394-398.

Taylor, B. and Powell, A. 1982. Isolation of plant DNA and RNA. Focus 4: 4-6.

Vettraino, A. M., Morel, O., Perlerou, C., Robin, C., Diamandis, S., and Vannini, A. 2005. Occurrence and distribution of Phytophthora species in European chestnut stands, and their association with ink disease and crown decline. European Journal of Plant Pathology 111: 169180.

White, R. P. 1930. Two Phytophthora diseases of rhododendron. Phytopathology 20: 131.

Wilkinson, C. J., Shearer, B. L., Jackson, T. J., and Hardy, G. E. St J. Variation in sensitivity of Western Australian isolates of Phytophthora cinnamomi to phosphite in vitro. Plant Pathol. 50: 83-89.

Wood, A. K. and Tainter, F. H. 2002. First report of Phytophthora cinnamomi on Quercus laurifolia. Plant Disease 86: 441.

Zentmyer, G. A. 1980. Phytophthora cinnamomi and the diseases it causes. Monograph No. 10 American Phytopathological Society, St. Paul, MN.

Zentmyer, G. A. and Guillemet, F. B. 1981. Evidence for strains of Phytophthora cinnamomi. Plant Disease 65: 475-477.

Zentmyer, G. A., Leary, J. V., Klure, L. J., and Grantham, G. L. 1976. Variability in growth of Phytophthora cinnamomi in relation to temperature. Phytopathology 66: 982-986. 